\title{
Sensitivity of stand transpiration to wind velocity in a mixed broadleaved deciduous forest
}

\section{Authors: Dohyoung Kim, Ram Oren, A. Christopher Oishi, Cheng-I. Hsieh, Nathan Phillips, Kimberly A. Novick, and Paul Stoy}

NOTICE: this is the author's version of a work that was accepted for publication in Agricultural and Forest Meteorology . Changes resulting from the publishing process, such as peer review, editing, corrections, structural formatting, and other quality control mechanisms may not be reflected in this document. Changes may have been made to this work since it was submitted for publication. A definitive version was subsequently published in Agricultural and Forest Meteorology, Volume 187, April 15, 2014, DOI\# 10.1016/j.agrformet.2013.11.013

Kim, Dohyoung, Ram Oren, A. Christopher Oishi, Cheng-I. Hsieh, Nathan Phillips, Kimberly A. Novick, and Paul Stoy. "Sensitivity of stand transpiration to wind velocity in a mixed broadleaved deciduous forest." Agricultural and Forest Meteorology 187 (2014): 62-71. 


\title{
Sensitivity of stand transpiration to wind velocity in a mixed broadleaved deciduous forest
}

\author{
Dohyoung Kim $^{\mathrm{a}, *}$, Ram Oren ${ }^{\mathrm{a}, \mathrm{b}}$, A. Christopher Oishi ${ }^{\mathrm{a}, \mathrm{g}}$, Cheng-I Hsieh ${ }^{\mathrm{c}}$, Nathan Phillips ${ }^{\mathrm{d}}$, \\ Kimberly A. Novick ${ }^{\mathrm{e}}$, Paul C. Stoy ${ }^{\mathrm{f}}$ \\ a Nicholas School of the Environment, Duke University, Box 90328, Durham, NC 27708-0328, USA \\ ${ }^{\mathrm{b}}$ Department of Forest Ecology \&'Management, Swedish University of Agricultural Sciences (SLU), SE-901 83 Umeå, Sweden \\ ${ }^{c}$ Department of Bioenvironmental Systems Engineering, National Taiwan University, No. 1, Section 4, Roosevelt Road, Taipei 10617, Taiwan \\ d Department of Geography and Environment, Boston University, 675 Commonwealth Avenue, Boston, MA 02215, USA \\ e School of Public and Environmental Affairs, Indiana University, 1315 East Tenth Street, Bloomington, IN 47405, USA \\ ${ }^{f}$ Department of Land Resources and Environmental Sciences, Montana State University, P.O. Box 172860, Bozeman, MT 59717-2860, USA \\ g USDA Forest Service, Southern Research Station, Coweeta Hydrologic Laboratory, 3160 Coweeta Lab Road, Otto, NC 28763, USA
}

\begin{abstract}
A B S T R A C T
Wind velocity $(U)$ within and above forest canopies can alter the coupling between the vapor-saturated sub-stomatal airspace and the drier atmosphere aloft, thereby influencing transpiration rates. In practice, however, the actual increase in transpiration with increasing $U$ depends on the aerodynamic resistance $\left(R_{\mathrm{A}}\right)$ to vapor transfer compared to canopy resistance to water vapor flux out of leaves $\left(R_{\mathrm{C}}\right.$, dominated by stomatal resistance, $R_{\text {stom }}$ ), and the rate at which $R_{\mathrm{A}}$ decreases with increasing $U$. We investigated the effect of $U$ on transpiration at the canopy scale using filtered meteorological data and sap flux measurements gathered from six diverse species of a mature broadleaved deciduous forest. Only under high light conditions, stand transpiration $\left(E_{\mathrm{C}}\right)$ increased slightly (6.5\%) with increasing $U$ ranging from $\sim 0.7$ to $\sim 4.7 \mathrm{~m} \mathrm{~s}^{-1}$. Under other conditions, sap flux density $\left(J_{\mathrm{S}}\right)$ and $E_{\mathrm{C}}$ responded weakly or did not change with $U$. $R_{\mathrm{A}}$, estimated from Monin-Obukhov similarity theory, decreased with increasing $U$, but this decline was offset by increasing $R_{\mathrm{C}}$, estimated from a rearranged Penman-Monteith equation, due to a concurrent increase in vapor pressure deficit $(D)$. The increase of $R_{C}$ with $D$ over the observed range of $U$ was consistent with increased $R_{\text {stom }}$ by $\sim 40 \%$ based on hydraulic theory. Except for very rare half-hourly values, the proportion of $R_{\mathrm{A}}$ to total resistance $\left(R_{\mathrm{T}}\right)$ remained $<15 \%$ over the observed range of conditions. These results suggest that in similar forests and conditions, the direct effect of $U$ reducing $R_{\mathrm{A}}$ and thus increasing transpiration is negligible. However, the observed $U-D$ relationship and its effect on $R_{\text {stom }}$ must be considered when modeling canopy photosynthesis.
\end{abstract}

\section{Introduction}

Because of their expanse, forests greatly impact the exchange of mass and energy between the biosphere and atmosphere with consequences ranging from effects on local weather conditions (Juang et al., 2007; Konings et al., 2011) to influences on global atmospheric circulation (Avissar and Werth, 2005; Bauerle and Bowden, 2011). Forests also play an important role in the provision of ecosystem services, including water yield, biomass production and carbon sequestration. Improved understanding of these exchanges and benefits involves a combination of observations and models. Estimates of mass (including carbon and water) and energy exchange between the biosphere and atmosphere commonly rely on modeled and measurement-based estimates of a series of resistances to these exchanges, each affected by biological and physical factors.

The flux of water vapor through stomata (i.e. transpiration) is an important flux since it represents the major component of water returned to the atmosphere from forests. Transpiration is also tightly coupled to $\mathrm{CO}_{2}$ exchange (i.e. canopy photosynthesis or gross primary production) because stomata serve as the common port for the fluxes of these gases. Thus, tree and ecosystem physiologists often investigate the sources of variation of resistances to water vapor flux in lieu of the variation of resistances to $\mathrm{CO}_{2}$ flux (Kim et al., 2008; Schäfer et al., 2003), and models often computationally link canopy $\mathrm{CO}_{2}$ uptake to transpiration via the carbon-based water-use efficiency (Running and Hunt, 1993). Transpiration is convenient flux to use in such analysis because, unlike $\mathrm{CO}_{2}$ flux, the dynamics of its exchange is straightforward to measure (Granier, 1987; Oishi et al., 2008; Oren et al., 1998; Schäfer et al., 2000). 


\title{
Sensitivity of stand transpiration to wind velocity in a mixed broadleaved deciduous forest
}

\author{
Dohyoung Kim ${ }^{\mathrm{a}, *}$, Ram Oren ${ }^{\mathrm{a}, \mathrm{b}}$, A. Christopher Oishi ${ }^{\mathrm{a}, \mathrm{g}}$, Cheng-I Hsieh ${ }^{\mathrm{c}}$, Nathan Phillips ${ }^{\mathrm{d}}$, \\ Kimberly A. Novick ${ }^{\mathrm{e}}$, Paul C. Stoy ${ }^{\mathrm{f}}$
}

a Nicholas School of the Environment, Duke University, Box 90328, Durham, NC 27708-0328, USA

${ }^{\mathrm{b}}$ Department of Forest Ecology \&'Management, Swedish University of Agricultural Sciences (SLU), SE-901 83 Umeå, Sweden

${ }^{c}$ Department of Bioenvironmental Systems Engineering, National Taiwan University, No. 1, Section 4, Roosevelt Road, Taipei 10617, Taiwan

d Department of Geography and Environment, Boston University, 675 Commonwealth Avenue, Boston, MA 02215, USA

e School of Public and Environmental Affairs, Indiana University, 1315 East Tenth Street, Bloomington, IN 47405, USA

${ }^{f}$ Department of Land Resources and Environmental Sciences, Montana State University, P.O. Box 172860, Bozeman, MT 59717-2860, USA

g USDA Forest Service, Southern Research Station, Coweeta Hydrologic Laboratory, 3160 Coweeta Lab Road, Otto, NC 28763, USA

\begin{abstract}
A B S T R A C T
Wind velocity $(U)$ within and above forest canopies can alter the coupling between the vapor-saturated sub-stomatal airspace and the drier atmosphere aloft, thereby influencing transpiration rates. In practice, however, the actual increase in transpiration with increasing $U$ depends on the aerodynamic resistance $\left(R_{\mathrm{A}}\right)$ to vapor transfer compared to canopy resistance to water vapor flux out of leaves $\left(R_{\mathrm{C}}\right.$, dominated by stomatal resistance, $R_{\text {stom }}$ ), and the rate at which $R_{\mathrm{A}}$ decreases with increasing $U$. We investigated the effect of $U$ on transpiration at the canopy scale using filtered meteorological data and sap flux measurements gathered from six diverse species of a mature broadleaved deciduous forest. Only under high light conditions, stand transpiration $\left(E_{\mathrm{C}}\right)$ increased slightly (6.5\%) with increasing $U$ ranging from $\sim 0.7$ to $\sim 4.7 \mathrm{~m} \mathrm{~s}^{-1}$. Under other conditions, sap flux density $\left(J_{\mathrm{S}}\right)$ and $E_{\mathrm{C}}$ responded weakly or did not change with $U$. $R_{\mathrm{A}}$, estimated from Monin-Obukhov similarity theory, decreased with increasing $U$, but this decline was offset by increasing $R_{\mathrm{C}}$, estimated from a rearranged Penman-Monteith equation, due to a concurrent increase in vapor pressure deficit $(D)$. The increase of $R_{C}$ with $D$ over the observed range of $U$ was consistent with increased $R_{\text {stom }}$ by $\sim 40 \%$ based on hydraulic theory. Except for very rare half-hourly values, the proportion of $R_{\mathrm{A}}$ to total resistance $\left(R_{\mathrm{T}}\right)$ remained $<15 \%$ over the observed range of conditions. These results suggest that in similar forests and conditions, the direct effect of $U$ reducing $R_{\mathrm{A}}$ and thus increasing transpiration is negligible. However, the observed $U-D$ relationship and its effect on $R_{\text {stom }}$ must be considered when modeling canopy photosynthesis.
\end{abstract}

\section{Introduction}

Because of their expanse, forests greatly impact the exchange of mass and energy between the biosphere and atmosphere with consequences ranging from effects on local weather conditions (Juang et al., 2007; Konings et al., 2011) to influences on global atmospheric circulation (Avissar and Werth, 2005; Bauerle and Bowden, 2011). Forests also play an important role in the provision of ecosystem services, including water yield, biomass production and carbon sequestration. Improved understanding of these exchanges and benefits involves a combination of observations and models. Estimates of mass (including carbon and water) and energy exchange between the biosphere and atmosphere commonly rely on modeled and measurement-based estimates of a series of resistances to these exchanges, each affected by biological and physical factors.

The flux of water vapor through stomata (i.e. transpiration) is an important flux since it represents the major component of water returned to the atmosphere from forests. Transpiration is also tightly coupled to $\mathrm{CO}_{2}$ exchange (i.e. canopy photosynthesis or gross primary production) because stomata serve as the common port for the fluxes of these gases. Thus, tree and ecosystem physiologists often investigate the sources of variation of resistances to water vapor flux in lieu of the variation of resistances to $\mathrm{CO}_{2}$ flux (Kim et al., 2008; Schäfer et al., 2003), and models often computationally link canopy $\mathrm{CO}_{2}$ uptake to transpiration via the carbon-based water-use efficiency (Running and Hunt, 1993). Transpiration is convenient flux to use in such analysis because, unlike $\mathrm{CO}_{2}$ flux, the dynamics of its exchange is straightforward to measure (Granier, 1987; Oishi et al., 2008; Oren et al., 1998; Schäfer et al., 2000). 
Table 1

Field studies that have investigated relationships between transpiration (or sap flux) and wind velocity.

\begin{tabular}{|c|c|c|c|c|c|c|}
\hline Correlation & Site description (species) & $\begin{array}{l}\text { Wind velocity } \\
\left(\mathrm{m} \mathrm{s}^{-1}\right)\end{array}$ & Tree stage(age in years) & $\mathrm{LAI}^{\mathrm{a}}$ & $\begin{array}{l}\operatorname{SLA}^{\mathrm{b}} \\
\left(\mathrm{cm}^{2} \mathrm{~g}^{-1}\right)\end{array}$ & Source \\
\hline \multirow[t]{5}{*}{ Positive } & $\begin{array}{l}\text { Hardwood, South Australia } \\
\text { (Eucalyptus globulus) }\end{array}$ & - & Young (7) & - & $62-192^{\mathrm{d}}$ & Taylor et al. (2001) \\
\hline & $\begin{array}{l}\text { Boreal mixedwood, Alberta, } \\
\text { Canada } \\
\text { (Picea glauca, P. balsamifera, } \\
\text { Betula papyrifera) }\end{array}$ & $0-2$ & Mature (45-50) & - & - & Bladon et al. (2006) \\
\hline & $\begin{array}{l}\text { Shrub, Tengger desert, China } \\
\text { (Artemisia ordosica) }\end{array}$ & - & $(10)$ & $0.5-0.9$ & - & Lei et al. (2010) \\
\hline & $\begin{array}{l}\text { Temperate hardwood, Estonia } \\
\text { (B. pendula, } P \text {. tremula }+P \text {. } \\
\text { tremuloides }^{\mathrm{C}} \text { ) }\end{array}$ & $0-4$ & Seedling (1) & - & - & Kupper et al. (2011) \\
\hline & $\begin{array}{l}\text { Temperate hardwood, China } \\
\text { (Populus alba) }\end{array}$ & $0-0.6$ & Young (7-10) & $0-2$ & $100-120^{\mathrm{d}}$ & Xu et al. (2006) \\
\hline \multirow[t]{2}{*}{ Negative } & $\begin{array}{l}\text { Shrub, island of Kauai, USA } \\
\text { (Coffea arabica L.) }\end{array}$ & $1-3$ & $(1-5.3)$ & $0.7-6.7$ & - & Gutiérrez et al. (1994) \\
\hline & $\begin{array}{l}\text { Hardwood, Wisconsin, USA } \\
\left(P . \text { nigra } \text { P. maximowiczii }{ }^{\mathrm{C}}\right)\end{array}$ & $0-4.5$ & Young & - & - & Zalesny et al. (2006) \\
\hline \multirow[t]{4}{*}{ Weak or none } & $\begin{array}{l}\text { Hardwood, Plauzat, France } \\
\text { (Juglans regia) }\end{array}$ & $0-4$ & Mature (20) & 9 & $82-398^{\mathrm{d}}$ & Daudet et al. (1999) \\
\hline & $\begin{array}{l}\text { Softwood, Chiba, Japan } \\
\text { (Cryptomeria japonica) }\end{array}$ & $0-1.5$ & Young (8) & 3.7 & - & Komatsu et al. (2006) \\
\hline & $\begin{array}{l}\text { Crop, Nebraska, USA } \\
\text { (Zea mays L.) }\end{array}$ & $0-7$ & - & $1-5$ & - & Irmak and Mutiibwa (2010) \\
\hline & $\begin{array}{l}\text { Temperate hardwood, Durham, } \\
\text { USA } \\
\text { (Liriodendron tulipifera, } \\
\text { Liquidambar styraciflua, Carya } \\
\text { tomentosa, Quercus alba, Q. } \\
\text { michauxii, Q. phellos) }\end{array}$ & $0.8-4.7$ & Mature (80-100) & 7.03 & $102-174$ & This study \\
\hline
\end{tabular}

Resistance to transpiration $\left(R_{\mathrm{T}}\right)$ can be partitioned into two serial components, bulk surface resistance $\left(R_{\text {sur }}\right)$ and aerodynamic resistance $\left(R_{\mathrm{A}}\right)$,

$R_{\mathrm{T}}=R_{\mathrm{sur}}+R_{\mathrm{A}}$

both of which depend on leaf physiology, canopy architecture and the atmospheric conditions above and within the canopy (Jones, 1992; Kumagai et al., 2004). $R_{\text {sur }}$ is generally attributed to canopy resistance $\left(R_{\mathrm{C}}\right)$ and soil (or forest floor) resistance $\left(R_{\text {soil }}\right)$ acting in parallel (Allen, 2005).

$R_{\text {sur }}=\frac{R_{\mathrm{C}} R_{\text {soil }}}{R_{\mathrm{C}}+R_{\text {soil }}}$

Soil evaporation is minor under high canopy leaf area, making $R_{\mathrm{C}}$ effectively equivalent to $R_{\text {sur }}$ when leaf area index (LAI) is greater than 3 (Kelliher et al., 1995; Waring, 2007). $R_{\mathrm{C}}$ can be expressed as a combination of stomatal resistance $\left(R_{\text {stom }}\right)$ and leaf boundary layer resistance $\left(R_{\mathrm{bl}}\right)$ in series (Aphalo and Jarvis, 1993):

$R_{\mathrm{C}}=R_{\mathrm{stom}}+R_{\mathrm{bl}}$

$R_{\text {stom }}$ reflects complex physiological responses of stomata to variation in atmospheric conditions, such as light availability, air temperature $\left(T_{\mathrm{a}}\right)$, humidity, $\mathrm{CO}_{2}$ concentration (Jarvis, 1976). $R_{\mathrm{bl}}$ is the resistance to vapor transfer within the air layer near leaf surface, and can be affected by wind velocity $(U)$, leaf shape, leaf size, edge characteristics, and surface structure (Schuepp, 1993; Stokes et al., 2006). $R_{\mathrm{bl}}$ is generally much smaller than $R_{\text {stom }}$ unless leaf size is large or $U$ is low (Aphalo and Jarvis, 1993; Schuepp, 1993).

Over time scales in which soil moisture and plant hydraulic properties (e.g. soil-to-leaf path-length, sapwood-to-leaf area ratio, hydraulic conductivity) can be considered invariable, $R_{\mathrm{C}}$ is largely determined by $R_{\text {stom. Jarvis (1976) described stomatal conductance }}$ (the inverse of $R_{\text {stom }}$ ) as a form of multiplicative function with photon flux density, vapor pressure deficit $(D), T_{\mathrm{a}}$, ambient $\mathrm{CO}_{2}$ concentration, and leaf water potential. Many formulations for $R_{\mathrm{stom}}$, ranging from empirical to theoretically-based functions have been proposed and used (Holmgren et al., 1996; Jonard et al., 2011; Launiainen et al., 2011; Pataki and Oren, 2003; Stewart, 1988), but except for allowing interactions among the controlling variables (Ward et al., 2008), this approach remained fundamentally unaltered. The other primary component of $R_{\mathrm{T}}, R_{\mathrm{A}}$, is determined by the physical conditions above and within the canopy, such as $U$, atmospheric stability, and canopy structure (Kumagai et al., 2004; Lindroth, 1993; Morris et al., 1998). Although estimates of $R_{\mathrm{A}}$ in forests are usually small relative to $R_{\mathrm{C}}$, reflected in that $R_{\mathrm{A}}$ is neglected in some biosphere-atmosphere exchange models (Granier et al., 2000; Kelliher et al., 1993; Köstner et al., 1992), few studies have actually quantified the effect of $U$ on $R_{\mathrm{A}}$ and, in-turn, on transpiration (Table 1 ). The results of these studies are inconclusive: some studies observed increased transpiration with $U$ (Chu et al., 2009; Grace and Russel, 1982; Kitaya et al., 2004); others observed a decline (Caldwell, 1970; Campbell-Clause, 1998; Dixon and Grace, 1984; Gutiérrez et al., 1994), or found transpiration to be insensitive to $U$ (Komatsu et al., 2006).

Here we analyze the effect of $U$ on transpiration through measurements and by quantifying the response to $U$ of estimated resistances in the water vapor pathway, focusing on the reduced expression:

$R_{\mathrm{T}}=R_{\mathrm{A}}+R_{\mathrm{bl}}+R_{\mathrm{stom}}$

Many of the studies on transpiration response to $U$ were performed in wind tunnels (Caldwell, 1970; Chu et al., 2009; Dixon and Grace, 1984; Grace and Russel, 1982; Kitaya et al., 2004). However, results of wind tunnel experiments may differ from those of field experiments because they do not account for the effect of neighboring crowns (shelter effect) on the coupling between stomata 


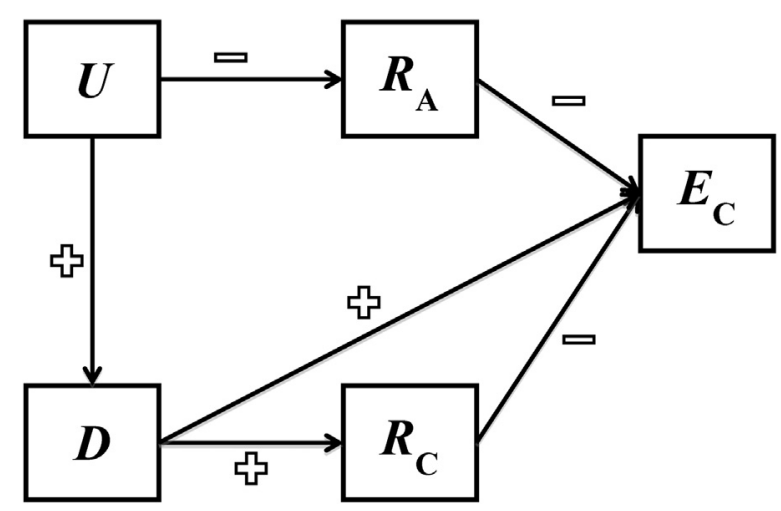

Fig. 1. Diagram showing the effect of wind velocity, $U$, on transpiration, $E_{\mathrm{C}}$ in a bigleaf framework. The sign represents the relationship between the two parameters at the arrow tip and tail ( $D$ - vapor pressure deficit; $R_{\mathrm{A}}$ - aerodynamic resistance; $R_{\mathrm{C}}$ - canopy resistance). For example, an increase in $U$ results in a decrease in $R_{\mathrm{A}}$ because of the negative relationship between $U$ and $R_{\mathrm{A}}$ and, in turn, the decrease in $R_{\mathrm{A}}$ leads to an increase in $E_{\mathrm{C}}$ because of the negative relationship between $R_{\mathrm{A}}$ and E.

and atmosphere in forest stands. In situ experiments were performed to overcome the limits of wind tunnels, but most have focused on crops and other small statured canopies; eight of the ten in situ studies we found were made on such canopies (Table 1). The response of these canopies to $U$ may differ from that of forests canopies which tend to be rougher, and thus better coupled to the atmosphere (Jones, 1992). Furthermore, the aerodynamic roughness of forest canopies depends on tree height, stand density, tree size distribution, and LAI, all of which change with stand age (Chapin, 2002; Perry, 2008). Thus, if $R_{\mathrm{A}}$ is actually large, it would require quantification for each combination of stand characteristics before estimating biosphere-atmosphere exchanges.

As LAI increases, $R_{C}$ decreases, improving the canopyatmosphere coupling (Granier and Bréda, 1996; Granier et al., 2000; Katsoulas et al., 2007), yet the increase in canopy leaf area may impede air movement, increasing $R_{\mathrm{A}}$ while decreasing $D$ within the canopy. At a given canopy LAI, as $U$ increases, the accompanying decrease of $R_{\mathrm{A}}$ allows for frequent replacement of moist canopy air with dry air from aloft, potentially driving more transpiration, yet the drier air may force stomatal closure and increase $R_{\text {stom }}$ (Fig. 1). Thus, the effect of $U$ on tree and canopy transpiration represents a balance among interacting processes and may not be simple to predict. Transpiration could therefore decrease with increasing $U$ if $R_{C}$ increases as a result of stomatal response to $D$, overwhelming both the decrease of $R_{\mathrm{A}}$ as well as the increase of $D$, the driving force for transpiration.

The goals of this study were to improve understanding of the effect of $U$ on transpiration. We assessed the response to $U$ of sap flux density $\left(J_{S}\right)$, a proxy of transpiration, of six co-occurring species, ranging in shade tolerance, leaf dimensions and leaf clumping, in a mature broadleaved deciduous forest, testing the following hypotheses: (H1) transpiration will increase with $U$ as a result of the combination of direct and indirect effects on resistances and forces above and within the canopy; $(\mathbf{H 2}) R_{\mathrm{A}}$ has a small effect on $R_{\mathrm{T}}$ meaning that $R_{\mathrm{T}}$ is dominated by the components of $R_{\text {sur }}$ (mostly $R_{\mathrm{C}}$, in-turn dominated by $R_{\mathrm{stom}}$ ); thus (H3) the response of $E_{\mathrm{C}}$ to $U$ will be determined by the effects of increases in $D$ with $U$ on $R_{\text {stom }}$ and the increase in the driving force, rather than by the direct effect of $U$ on $R_{\mathrm{A}}$ and $R_{\mathrm{bl}}$.

\section{Materials and methods}

\subsection{Site description and data collection}

The study was conducted at the Duke Forest hardwood site, North Carolina $\left(36^{\circ} 58^{\prime} \mathrm{N}, 79^{\circ} 05^{\prime} \mathrm{W}\right.$ ) from 2002 to 2005 . The maximum tree age of the hardwood stand is $\sim 100$ years. Mean and maximum canopy heights of the stand are $25 \mathrm{~m}$ and $35 \mathrm{~m}$, respectively (Pataki and Oren, 2003). A total of 40 trees of the six dominant species, yellow (tulip) poplar (Liriodendron tulipifera), sweetgum (Liquidambar styraciflua), hickory (Carya tomentosa), white oak (Quercus alba), swamp chestnut oak (Q. michauxii), and willow oak (Q. phellos), were selected for sap flux measurement (Table 2). $J_{S}$ was measured with $20 \mathrm{~mm}$ long Granier-type heat dissipation sensors (Granier, 1987). The Granier-type technique has a potential to produce bias of $J_{S}$ due to its sensitivity to physical factors including thermal conductivity of sapwood, temperature gradients within sapwood, and variation in $J_{S}$ with sapwood depth (Tatarinov et al., 2005; Wullschleger et al., 2011). However, using the same data, Oishi et al. (2010) showed that $J_{S}$ produced similar estimates of latent heat flux when properly scaled to the site's eddy-covariance footprint. The measurement depths varied from $0-20$ to $0-60 \mathrm{~mm}$ based on the expected depth of sapwood; sensors generating values at least two standard deviations apart from values collected by others in the same species and measurement depth were excluded to avoid potential underestimation caused by excessive penetration into heartwood (Lu et al., 2004).

$T_{\mathrm{a}}$ and relative humidity were measured at two-thirds of the mean canopy height with a temperature/RH probe (HMP35C, Campbell Scientific, Logan, UT, USA), and used to calculate $D$ (Campbell and Norman, 1998). Photosynthetically active radiation (PAR) was measured above the canopy using a quantum sensor (LI190SA, LI-COR, Lincoln, NE, USA). Volumetric soil moisture $(\theta)$ was measured in 12 locations, at $5-10 \mathrm{~cm}$ and $20-25 \mathrm{~cm}$ in each location, using ThetaProbe sensors (ML2x, Delta-T Devices, Cambridge, UK). $U$ was measured with a tri-axial sonic anemometer installed above the canopy at $39.8 \mathrm{~m}$ (CSAT3, Campbell Scientific, Logan, UT,

Table 2

Characteristics of sampled trees at the Duke Forest hardwood site. Standard deviations are shown in parentheses.

\begin{tabular}{|c|c|c|c|c|c|c|c|}
\hline Species & $\mathrm{DBH}^{\mathrm{a}}$ & $\mathrm{LAD}^{\mathrm{b}}$ & $J_{\mathrm{S}}{ }^{\mathrm{c}}$ & $A_{\mathrm{S}}^{\mathrm{d}}$ & SLA $^{\mathrm{e}}$ & $d^{\mathrm{f}}$ & Number of trees \\
\hline L. tulipifera & $39.3(14.96)$ & 0.017 & $42.36(15.21)$ & 2.37 & 161.8 & 8.3 & 10 \\
\hline L. styraciflua & $36.58(12.16)$ & 0.020 & $29.44(13.10)$ & 2.09 & 102.4 & 8.1 & 10 \\
\hline Other diffuse porous & - & - & - & 1.48 & 173.3 & - & - \\
\hline C. tomentosa & $34.12(20.86)$ & 0.062 & $36.32(15.30)$ & 2.11 & 131.9 & 4.7 & 5 \\
\hline Q. alba & $32.34(18.46)$ & 0.018 & $42.30(12.61)$ & 0.52 & 112.2 & 5.4 & 5 \\
\hline Q. michauxii & $33.68(16.80)$ & 0.014 & $37.55(10.40)$ & 0.59 & 128.9 & 6.8 & 5 \\
\hline Q. phellos & $49.48(9.02)$ & 0.003 & $43.88(10.28)$ & 0.27 & 101.9 & 1.1 & 5 \\
\hline Other ring porous & - & - & - & 0.60 & - & - & - \\
\hline
\end{tabular}

a Diameter at breast height $(\mathrm{cm})$.

b Leaf area density $\left(\mathrm{m}^{2} \mathrm{~m}^{-3}\right)$.

c verage sap flux density $\left(\mathrm{g} \mathrm{H}_{2} \mathrm{O} \mathrm{m}^{-2} \mathrm{~s}^{-1}\right)$ from selected data.

d Sapwood area $\left(\mathrm{cm}^{2} \mathrm{~m}^{-2}\right)$ weighed based on radial profiles of $J_{\mathrm{S}}$ (Oishi et al., 2008).

e Specific leaf area $\left(\mathrm{cm}^{2} \mathrm{~g}^{-1}\right)$.

f Leaf characteristic dimension (cm; Harlow et al., 1996). 


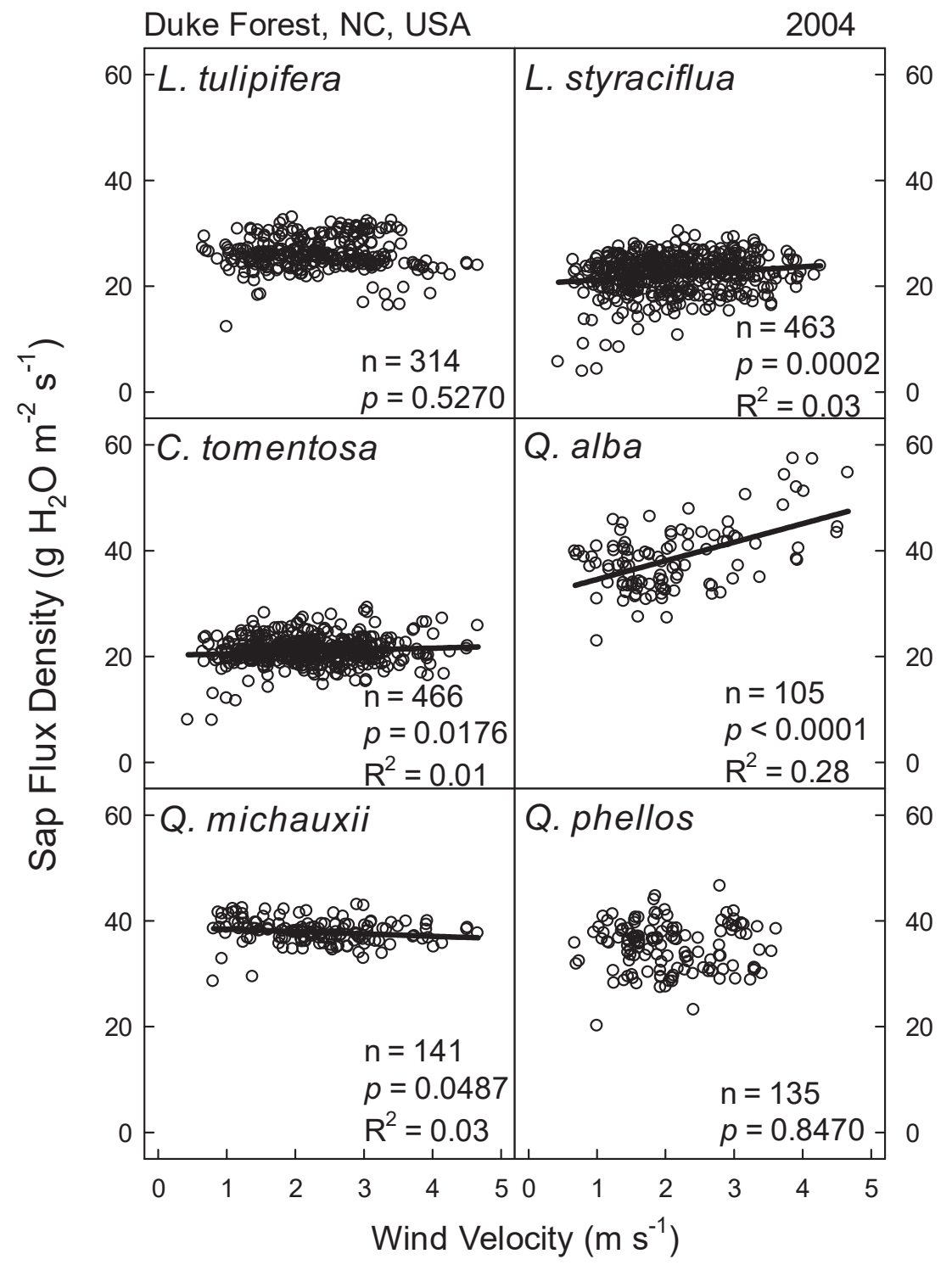

Fig. 2. The effect of wind velocity on sap flux density of six species in the Duke Forest hardwood site. Solid lines represent significant relationships at $p<0.05$.

USA). More details on the site and measurements are given in previous publications on the stand (Oishi et al., 2008; Pataki and Oren, 2003; Stoy et al., 2006). Thirty-minute averages of all the measurements were stored on data loggers (CR23X, Campbell Scientific, Logan, UT, USA).

\subsection{Data preparation}

To minimize the effects of meteorological variables other than $U$, we selected data during times in which leaf area index is reasonably stable (DOY 120-275, excluding the short period of fast leaf expansion and the long period of leaf abscission and shedding) and conditions where transpiration is not likely limited by $T_{\mathrm{a}}\left(\geq 25^{\circ} \mathrm{C}\right)$ and $\theta\left(\geq 0.2 \mathrm{~m}^{3} \mathrm{~m}^{-3}\right)$. Data under these conditions were further partitioned to four ranges of light (PAR, at $500 \mu \mathrm{mol} \mathrm{m}^{-2} \mathrm{~s}^{-1}$ up to $1500 \mu \mathrm{mol} \mathrm{m}^{-2} \mathrm{~s}^{-1}$, and one class for data under $P A R \geq 1500 \mu \mathrm{mol} \mathrm{m}^{-2} \mathrm{~s}^{-1}$, on which we concentrated most of the analyses for reasons that will become clear later).

$J_{S}$ varies greatly among sensors (Granier, 1987). Typically, before estimating species or stand scale transpiration, missing data is gap-filled to avoid the effect on the average $J_{S}$ of single sensors dropping in and out of the data set. However, we chose a conservative approach, relying on only operating sensors, selecting the largest number of sensors for each species resulting in at least 3000 half-hourly, species level averages over the study period, all produced by the same three to five sensors. The $2003 J_{S}$ data of Q. michauxii were excluded from analysis because the values were unstable. When calculating stand-scale $E_{C}$, missing average $J_{S}$ of any species ( $\sim 54 \%$ of potential values) resulted in missing half-hourly stand-scale $E_{\mathrm{C}}$. To gap-fill the missing average $J_{S}$, a power function $\left(y=a+b x^{n}\right)$ was fitted among species when average $J_{S}$ of at least three species were available ( $\sim 64 \%$ of the time under the selected conditions). If the data of more than three species at a given halfhour were missing, the data were neither gap-filled nor used for $E_{C}$ calculation; otherwise, missing data of a species were gap-filled using data of another species with the best fit in terms of $R^{2}$ value. Approximately $50 \%$ of the missing data were gap-filled. The performance of the gap-filling procedure was evaluated by comparing the data unused in developing the gap-filling functions ( $\sim 36 \%$ of the time, when data for only one or two species were available) and estimates based on the function developed for each species. The estimated values were well fitted with observed ones $\left(R^{2}>0.89\right.$; slope ranged from 0.88 to 1.10 ). 


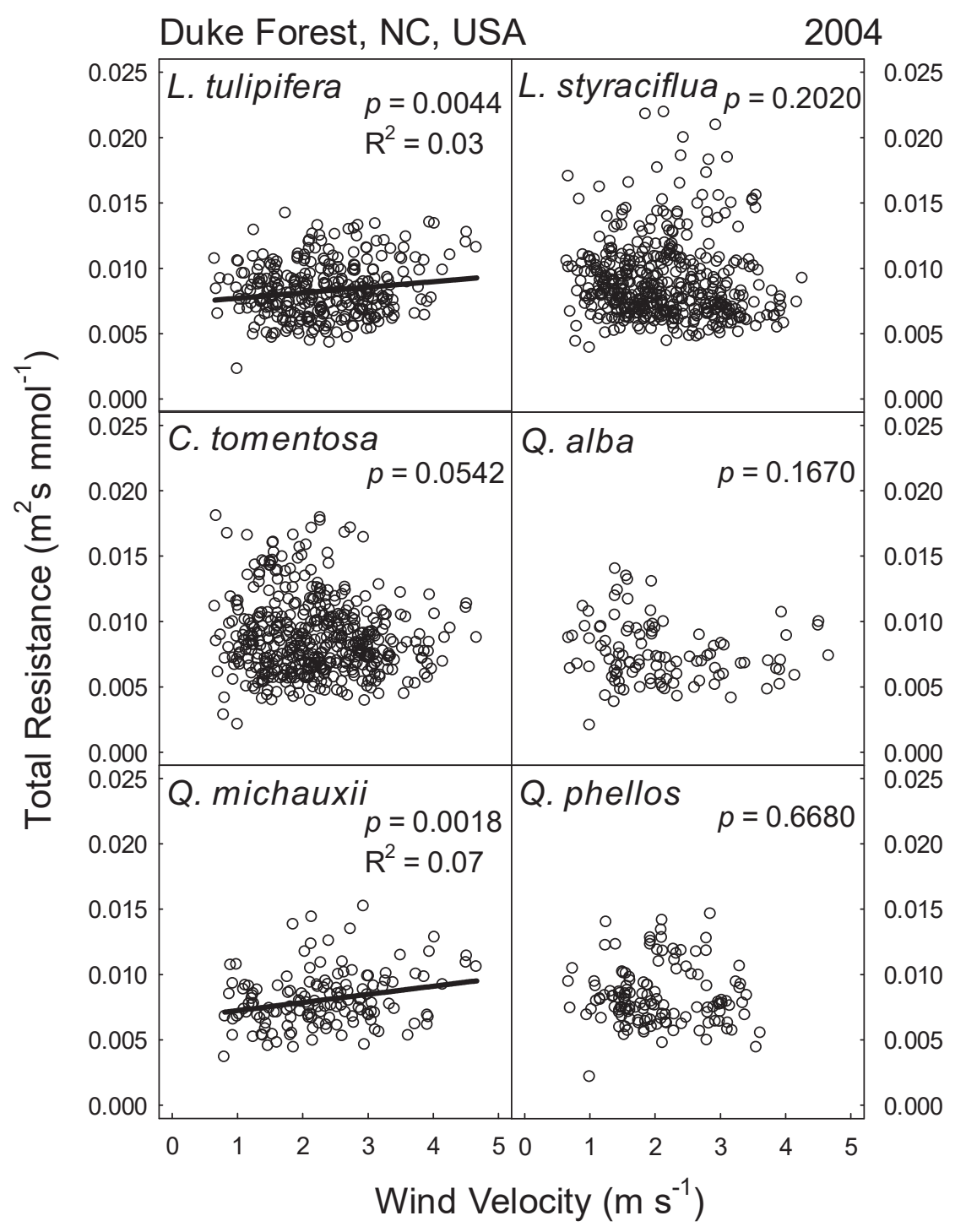

Fig. 3. The relationship between wind velocity and total resistance. Solid lines represent significant relationships at $p<0.05$.

$R_{\mathrm{A}}$ in the air layer above the canopy surface was estimated by Monin-Obukhov similarity theory (Campbell and Norman, 1998):

$R_{\mathrm{A}}=\frac{\left[\ln \left((z-d) / z_{\mathrm{om}}\right)+\Psi_{\mathrm{M}}\right]\left[\ln \left((z-d) / z_{\mathrm{oh}}\right)+\Psi_{\mathrm{H}}\right]}{k^{2} \hat{\rho} U}$

$$
\times\left(\mathrm{m}^{2} \mathrm{~s} \mathrm{mmol}^{-1}\right)
$$

$\Psi_{\mathrm{H}}= \begin{cases}6 \ln (1+\zeta), & \text { for stable flow } \\ -2 \ln \left[\frac{1+(1-16 \zeta)^{1 / 2}}{2}\right], & \text { for unstable flow }\end{cases}$

$\Psi_{\mathrm{M}}= \begin{cases}\Psi_{\mathrm{H}}, & \text { for stable flow } \\ 0.6 \Psi_{\mathrm{H}}, & \text { for unstable flow }\end{cases}$

where $\hat{\rho}$ is the molar density of air $\left(\mathrm{mmol} \mathrm{m}^{-3}\right), k(=0.4)$ is the von Karman constant, $U$ is the wind velocity $\left(\mathrm{m} \mathrm{s}^{-1}\right), z$ is the height of measured wind velocity $(\mathrm{m}), d$ is the zero plane displacement $(\mathrm{m})$, $z_{\text {om }}$ is the momentum roughness length $(\mathrm{m}), z_{\mathrm{oh}}$ is the scalar roughness length for heat transfer $(\mathrm{m}), \Psi_{\mathrm{M}}$ and $\Psi_{\mathrm{H}}$ are the profile diabatic correction factors for buoyant instability, $\zeta$ is the atmospheric stability. The parameters $d, z_{\mathrm{om}}$, and $z_{\mathrm{oh}}$ were taken as fixed values, $0.67,0.1$, and 0.02 of the canopy height in this study, making the effect of the surface roughness length constant during the growing season. A $10 \%$ variation of each of the three parameters changed the maximum of calculated values of $R_{\mathrm{A}}$ by $2.8,1.8$, and $1.7 \%$, supporting the assumption of constant parameters.

$R_{\mathrm{C}}$ was obtained by subtracting $R_{\mathrm{A}}$ from the total resistance $\left(R_{\mathrm{T}}\right)$, which was calculated from a rearranged Penman-Monteith equation after Blanken and Black (2004):

$R_{\mathrm{T}}=\frac{s}{\gamma} \beta R_{\mathrm{A}}+\frac{\rho c_{\mathrm{p}} D}{\hat{\rho} \gamma \lambda E_{\mathrm{C}}}\left(\mathrm{m}^{2} \mathrm{~s} \mathrm{mmol}^{-1}\right)$

where $s$ is the slope of the saturation vapor pressure with $T_{\mathrm{a}}$ $\left(\mathrm{kPa} \mathrm{K}^{-1}\right), \gamma$ is the psychrometric constant $\left(\mathrm{kPa} \mathrm{K}^{-1}\right), \beta$ is the Bowen ratio (ratio of sensible to latent heat fluxes), $\rho$ is the density of air $\left(\mathrm{kg} \mathrm{m}^{-3}\right), c_{\mathrm{p}}$ is the specific heat of $\operatorname{air}\left(\mathrm{J} \mathrm{kg}^{-1} \mathrm{~K}^{-1}\right), D$ is the vapor pressure deficit $(\mathrm{kPa}), \lambda$ is the latent heat of vaporization $\left(\mathrm{Jg}^{-1}\right)$, and $E_{\mathrm{C}}$ is the canopy transpiration $\left(\mathrm{g} \mathrm{H}_{2} \mathrm{O} \mathrm{m}^{-2}\right.$ (ground area) $\mathrm{s}^{-1}$ ). Typical values of $\beta$ for temperate forests (lower in deciduous than in conifer forests) ranged from 0.4 to 0.8 (Novel, 2005; Wilson et al., 2002). Since a change of $\beta$ by 0.1 within the range resulted in only $2.5 \%$ difference in $R_{\mathrm{T}}$ under the selected conditions in this study, $\beta$ was 
assumed to be constant (0.5). $E_{C}$ was estimated with $J_{S}$ from outer sensors (depth of $0-20 \mathrm{~mm} ; \mathrm{g} \mathrm{H}_{2} \mathrm{O} \mathrm{m}^{-2}$ (sapwood area) $\mathrm{s}^{-1}$ ) and cross-sectional sapwood area per unit ground area $\left(A_{S} ; \mathrm{cm}^{2} \mathrm{~m}^{-2}\right)$ weighed using radial profiles of $J_{S}$. The weighed $A_{S}$ of each species was obtained from allometric relationship between diameter at breast height and sapwood area (Oishi et al., 2008, 2010).

To assess the importance of $R_{\mathrm{bl}}$ in this stand, species mean $R_{\mathrm{bl}}$ values were calculated using an equation for the resistance of vapor transport in forced convection (Campbell and Norman, 1998), which dominates over free convection in this canopy (Stoy et al., 2006):

$R_{\mathrm{bl}}=\frac{v^{1 / 6}}{0.664 \hat{\rho} D_{\mathrm{v}}^{2 / 3}} \sqrt{\frac{d_{\mathrm{l}}}{u}}=0.0068 \sqrt{\frac{d_{\mathrm{l}}}{u}}\left(\mathrm{~m}^{2} \mathrm{~s}^{1 / 2} \mathrm{mmol}^{-1}\right)$

where $v$ is the kinematic viscosity of air $\left(\mathrm{m}^{2} \mathrm{~s}^{-1}\right), D_{\mathrm{v}}$ is the molecular diffusivity of water vapor in air $\left(\mathrm{m}^{2} \mathrm{~s}^{-1}\right), d_{1}$ is the leaf characteristic dimensions (0.011-0.083 m; Table 2), and $u$ is the vertically averaged $U$ within canopy $\left(\mathrm{m} \mathrm{s}^{-1}\right)$. A constant value of $0.0068 \mathrm{~m}^{2} \mathrm{~s}^{1 / 2} \mathrm{mmol}^{-1}$ was used for $v^{1 / 6}\left(0.664 \hat{\rho} D_{\mathrm{v}}^{2 / 3}\right)^{-1}$ (Campbell and Norman, 1998). $u$ was estimated based on $U$ profiles within canopy and LAI profile when canopy leaf area was at its stable seasonal plateau (DOY 154):

$u=\frac{\sum_{h=1}^{H} U(h) \operatorname{LAI}(h)}{\sum_{h=1}^{H} \operatorname{LAI}(h)}$

where $U(h)$ and $\operatorname{LAI}(h)$ are $U$ and LAI at a height $h$ within canopy, and $H$ is the canopy height $(\mathrm{m})$. The $U$ profiles were calculated as (Campbell and Norman, 1998):

$U(h)=u_{0} e^{a((h / H)-1)}$

where $u_{0}$ is the $U$ at the top of the canopy and $a$ is an attenuation coefficient (assumed to be 2.5). The LAI profile was estimated from measurements at $\sim 2 \mathrm{~m}$ intervals from 1 to $45 \mathrm{~m}$ along a tower using an optical plant canopy analyzer (LAI-2000, LI-COR, Lincoln, NE, USA; Stoy et al., 2005).

Also, to understand the coupling between the air within and above the canopy volume, the decoupling coefficient for the canopy $(\Omega)$ was considered. In this study $\Omega$ was calculated using Jarvis and Mcnaughton (1986):

$\Omega=\frac{(s / \gamma)+1}{(s / \gamma)+1+\left(R_{\mathrm{C}} / R_{\mathrm{A}}\right)}$

$\Omega$ approaches zero when the ratio $R_{\mathrm{C}} / R_{\mathrm{A}}$ approaches infinity, a condition of perfect coupling between the air in the canopy volume and the bulk air above the canopy (i.e. very efficient mass and energy exchange), resulting in essentially identical $T_{\mathrm{a}}$ and humidity in these two locations. If $R_{\mathrm{A}}$ is much larger than $R_{\mathrm{C}}, \Omega$ approaches one, reflecting the isolation of the air in the canopy volume from that aloft.

\section{Results and discussion}

\subsection{Sap flux density}

We first examined the relationship between $U$ and $J_{S}$. We used a subset of the available data to minimize the effects of other variables including light, temperature, and soil water. The means (and ranges) of $T_{\mathrm{a}}$, PAR, $\theta, D$, and $U$ of the selected data were $29.0 \quad(25.0-35.1)^{\circ} \mathrm{C}, \quad 1662 \quad(1500-2047) \mu \mathrm{mol} \mathrm{m}^{-2} \mathrm{~s}^{-1}$,

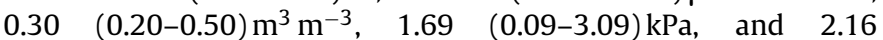
$(0.44-5.09) \mathrm{m} \mathrm{s}^{-1}$, respectively. Although the size of the subset is only $5.3 \%$ of total daytime of the stable LAI period (but see below), the range of $U$ includes $98.3 \%$ of the range of $U$ during daytime hours of the growing season above this stand. The average
JS of L. tulipifera, L. styraciflua, C. tomentosa, Q. alba, Q. michauxii, and $Q$. phellos after the filtering were 26.0, 22.1, 20.9, 38.5, 37.8, and $35.0 \mathrm{~g} \mathrm{H}_{2} \mathrm{O} \mathrm{m}^{-2}$ (sapwood area) $\mathrm{s}^{-1}$, respectively.

Fig. 2 shows the relationship between 30 min average $J_{S}$ of the six species and $U$ during the growing season. Over the wide range of $U, J_{S}$ of $L$. tulipifera and $Q$. phellos did not change significantly. For $L$. styraciflua, C. tomentosa, $Q$. alba, and $Q$. michauxii, the relationships were weak $\left(R^{2}=0.01-0.28\right)$ and inconsistent in sign. The sensitivity of $J_{S}$ to $U$ can be influenced by different leaf size among species because specific leaf dimension (i.e. leaf width in the direction of the wind) changes the leaf boundary layer thickness (Campbell and Norman, 1998). However, no effect of leaf size on the $J_{S}-U$ sensitivity was observed among species $(p=0.796)$.

Observations of the relationship between $U$ and sap flux (or tree transpiration) were diverse. For example, increasing $U$ by up to $2 \mathrm{~m} \mathrm{~s}^{-1}$ by partially harvesting a boreal stand composed of Picea glauca, P. balsamifera, and Butula papyrifera increased transpiration per unit leaf area (Bladon et al., 2006), but sap flux of hybrid poplar (Populus nigra L. $\times$ P. maximowiczii A. Henry) was negatively correlated to $U$ (Zalesny et al., 2006). Komatsu et al. (2006) found no difference of sap flux of Cryptomeria japonica under a given $D$ at all $U>0.7 \mathrm{~m} \mathrm{~s}^{-1}$. In a study of 7-year-old Eucalyptus globulus the ratio of sap flux of edge trees to that of trees far from the edge increased with $U$ when $R_{C}$ of edge trees was sufficiently low to cause leaf temperature to equal $T_{\mathrm{a}}$ (Taylor et al., 2001). Similarly at the individual crown scale, simulated transpiration of 20-year-old Juglans regia foliage increased slightly as $U$ increased from 1 to $5 \mathrm{~m} \mathrm{~s}^{-1}$ in shaded leaves but was insensitive to $U$ in sunlit leaves that had higher leaf temperature than $T_{\mathrm{a}}$ (Daudet et al., 1999). The results of these studies demonstrate the complex effect $U$ can have on stand transpiration.

\subsection{Total, aerodynamic, and canopy resistance}

In order to examine how $U$ affected resistances, we first calculated $R_{\mathrm{T}}$ for each species from its $J_{\mathrm{S}}$ and $A_{\mathrm{S}}$, as if the stand was entirely composed by that species (Fig. 3). The mean $R_{\mathrm{T}}$ values of each species (L. tulipifera, L. styraciflua, C. tomentosa, $Q$. alba, $Q$. michauxii, and $Q$. phellos) were $0.83 \times 10^{-2}, 0.89 \times 10^{-2}$, $0.87 \times 10^{-2}, 0.75 \times 10^{-2}, 0.81 \times 10^{-2}$, and $0.83 \times 10^{-2} \mathrm{~m}^{2}$ (ground area) $\mathrm{s} \mathrm{mmol}{ }^{-1}$, respectively. $R_{\mathrm{T}}$ weakly increased with $U$ for two species in the stand (L. tulipifera and Q. michauxii; Fig. 3).

Stand-level $R_{\mathrm{T}}$ based on the actual species composition was calculated using sap flux-scaled canopy transpiration $\left(E_{\mathrm{C}}\right) . E_{\mathrm{C}}$ was unrelated to $U$ in three PAR intervals $(0-500,500-1000$, and $\left.1000-1500 \mu \mathrm{mol} \mathrm{m}^{-2} \mathrm{~s}^{-1}\right)$ when analyzed along the entire range of $U$ found in each interval ( $p=0.0746,0.3710$, and 0.0707; Fig. 4a). In the highest PAR interval $\left(\geq 1500 \mu \mathrm{mol} \mathrm{m}^{-2} \mathrm{~s}^{-1}\right)$, a weak positive relationship was observed between $E_{C}$ and $U\left(p=0.0069, R^{2}=0.02\right)$. However, the increase of $E_{\mathrm{C}}$ associated with $\sim 7$-fold increase of $U$ was only $6.5 \%$. Thus, we must reject H1: under most conditions, stand transpiration did not increase with $U$.

Although $R_{\mathrm{T}}$ increased with $U$ for two species, the relationship between stand-level $R_{\mathrm{T}}$ and $U$ was not significant ( $p=0.3650$; Fig. 4b). Because of the observed lack of or limited sensitivity of $E_{C}$ to $U$ in any PAR range, we concentrate our analyses on only the one set of conditions in which no environmental variable was limiting, thus reducing the variation in the calculated resistances. The direct effect of $U$ on water transport through the air layer above the canopy is reflected in $R_{\mathrm{A}}$. The average $R_{\mathrm{A}}$ of this stand was $4.62 \times 10^{-4} \mathrm{~m}^{2}$ (ground area) $\mathrm{smmol}^{-1}$, within the range of values from other broadleaved forest stands (Köstner et al., 1992; Kumagai et al., 2004; Lindroth, 1993; Pereira et al., 2010). The estimated values of $R_{\mathrm{A}}$ over the canopy decreased from $1.31 \times 10^{-3}$ to $1.95 \times 10^{-4} \mathrm{~m}^{2}$ (ground area) $\mathrm{smmol}^{-1}$ as $U$ increased from $\sim 0.7$ to $\sim 4.7 \mathrm{~m} \mathrm{~s}^{-1}$ (Fig. $4 \mathrm{c}$ ). However, consistent with $\mathbf{H 2}, R_{\mathrm{A}}$ was a 
Duke Forest, NC, USA

2004

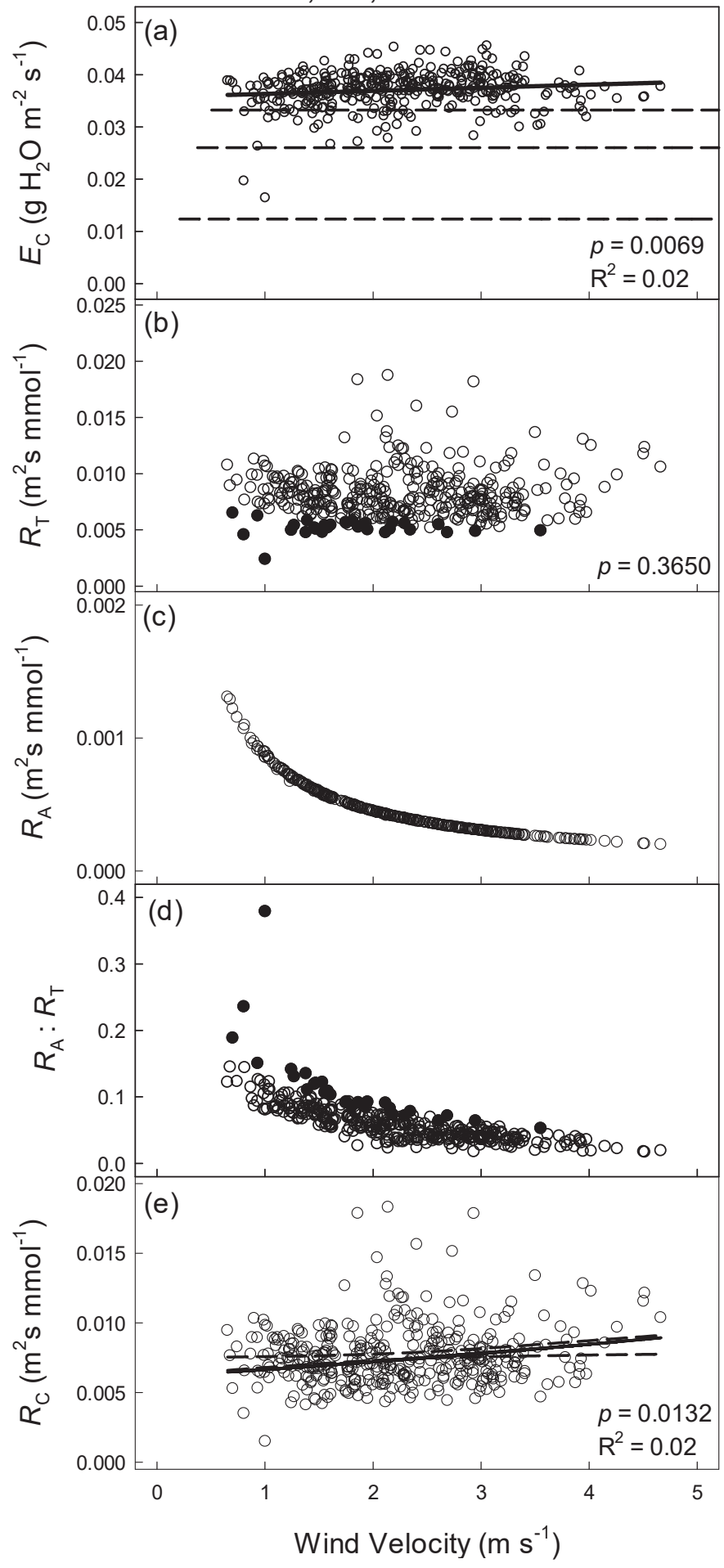

Fig. 4. Changes in stand-level transpiration and resistances with increasing wind velocity $(U)$. (a) Canopy transpiration $\left(E_{\mathrm{C}}\right)$; dashed lines from the bottom up represent light conditions of $500 \mu \mathrm{mol} \mathrm{m}^{-2} \mathrm{~s}^{-1}$ intervals from 0 to $1500 \mu \mathrm{mol} \mathrm{m}^{-2} \mathrm{~s}^{-1}$ while the data points represent conditions of $>1500 \mu \mathrm{mol} \mathrm{m}^{-2} \mathrm{~s}^{-1}$. Only one PAR interval $\left(>1500 \mu \mathrm{mol} \mathrm{m}^{-2} \mathrm{~s}^{-1}\right)$ showed significant yet very weak correlation (solid line). (b) total resistance $\left(R_{\mathrm{T}}\right)$; filled circles represent $R_{\mathrm{T}}$ when vapor pressure deficit (D) is low ( $<1 \mathrm{kPa}$ ), (c) aerodynamic resistance $\left(R_{\mathrm{A}}\right)$, (d) proportion of $R_{\mathrm{A}}$ to $R_{\mathrm{T}}$; filled circles represent the proportion when $D$ is low $(<1 \mathrm{kPa})$, and (e) canopy resistance $\left(R_{\mathrm{C}}\right)$ with $95 \%$ confidence intervals for individual estimates (dashed lines) and expected $R_{\text {stom }}$ based on the relationship between $R_{\text {stom }}$ and vapor pressure deficit (D), and between $D$ and $U$ (solid line; see text).
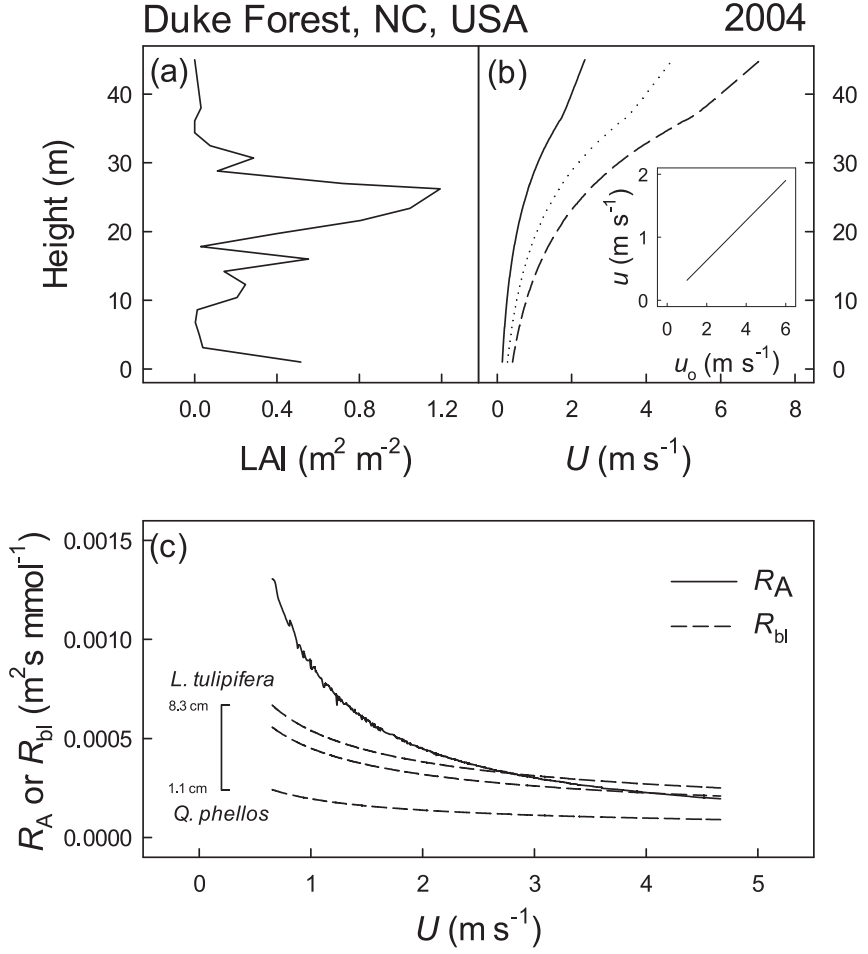

Fig. 5. (a) Leaf area index (LAI) profile (DOY 154). (b) Calculated wind velocity $(U)$ profiles above and within the canopy when $U$ at measurement height $(39.8 \mathrm{~m})$ are 2 (solid line), 4 (dotted line), and $6 \mathrm{~m} \mathrm{~s}^{-1}$ (dashed line). Inset figure shows the relationship between $U$ above canopy $\left(u_{0}\right)$ and average $U$ within canopy weighted by leaf area profile $(u)$. (c) Aerodynamic resistance $\left(R_{\mathrm{A}}\right.$; solid line) and leaf boundary layer resistance ( $R_{\mathrm{bl}}$; dashed lines) estimated using $U$ and leaf characteristic dimensions of the six species, ranged from $1.1 \mathrm{~cm}$ for $Q$. phellos to $8.6 \mathrm{~cm}$ for $L$. tulipifera (see Table 2); the dashed lines from the top represent $R_{\mathrm{bl}}$ estimates of $L$. tulipifera, weighed average, and Q. phellos.

relatively small component of $R_{\mathrm{T}}$, decreasing from $15 \%$ to $1.6 \%$ with increasing $U$ except three half-hourly values with $18.8,23.5$ and $37.8 \%$ due to exceptionally low $D(0.10,0.31$ and $0.97 \mathrm{kPa}$; Fig. $4 \mathrm{~d})$. When $D$ was low, $R_{\mathrm{T}}$ was generally lower under all $U$ condition, and thus the ratio of $R_{\mathrm{A}}$ to $R_{\mathrm{T}}$ increased somewhat with decreasing $D$ (see Fig. $4 \mathrm{~b}$ and d).

$R_{\mathrm{C}}$, calculated by subtracting $R_{\mathrm{A}}$ from $R_{\mathrm{T}}$, increased with $U$ in the stand $\left(p=0.0132 ; R^{2}=0.2\right.$; Fig. $\left.4 \mathrm{e}\right)$. The mean $R_{\mathrm{C}}$ of the stand was $7.61 \times 10^{-3} \mathrm{~m}^{2}$ (ground area) $\mathrm{s} \mathrm{mmol}^{-1}$, similar to values observed in other broadleaved forest stands (Blanken and Black, 2004; Hinckley et al., 1994). In a Coffea arabica plantation, $R_{\mathrm{C}}$ normalized by PAR also increased with increasing $U$ from 1 to $2.5 \mathrm{~m} \mathrm{~s}^{-1}$ (Gutiérrez et al., 1994), as it did, albeit weakly, in a Zea mays field (Irmak and Mutiibwa, 2010).

We assessed the contribution of $R_{\mathrm{bl}}$ to $R_{\mathrm{C}}$ modeling the wind velocity profile down the canopy based on leaf-area profile and characteristic leaf dimensions (Fig. $5 a$ and $b$ ). The maximum values of $R_{\mathrm{bl}}$ of the six species ranged from $2.76 \times 10^{-4}$ to $7.64 \times 10^{-4} \mathrm{~m}^{2}$ (ground area) $\mathrm{s} \mathrm{mmol}{ }^{-1}$, an order of magnitude smaller than $R_{\mathrm{C}}$ over much of the range of $U$ in this stand (Figs. $4 \mathrm{e}$ and $5 \mathrm{c}$ ). Indeed, $R_{\mathrm{bl}}$ was less than half of $R_{\mathrm{A}}$ at low $U$, becoming similar to $R_{\mathrm{A}}$ only at very high $U$ when the sum of both resistances was a very small component of the total. Thus, $R_{\mathrm{stom}}$ is much greater than $R_{\mathrm{bl}}$ and can be assumed equivalent to $R_{\mathrm{C}}$. We test this assumption when we address $\mathbf{H} \mathbf{3}$ in the last section.

The small absolute decrease of $R_{\mathrm{A}}$ with increasing $U$, and the low ratio of $R_{\mathrm{A}}$ to $R_{\mathrm{T}}$ at our stand indicate that the stand was generally well-coupled to the atmosphere (mean $\Omega=0.22$; Fig. 6a) despite its high tree density ( $\sim 866$ total trees per hectare), extensive vertical distribution of foliage ( $\sim 685$ of $\sim 866$ trees were in the 

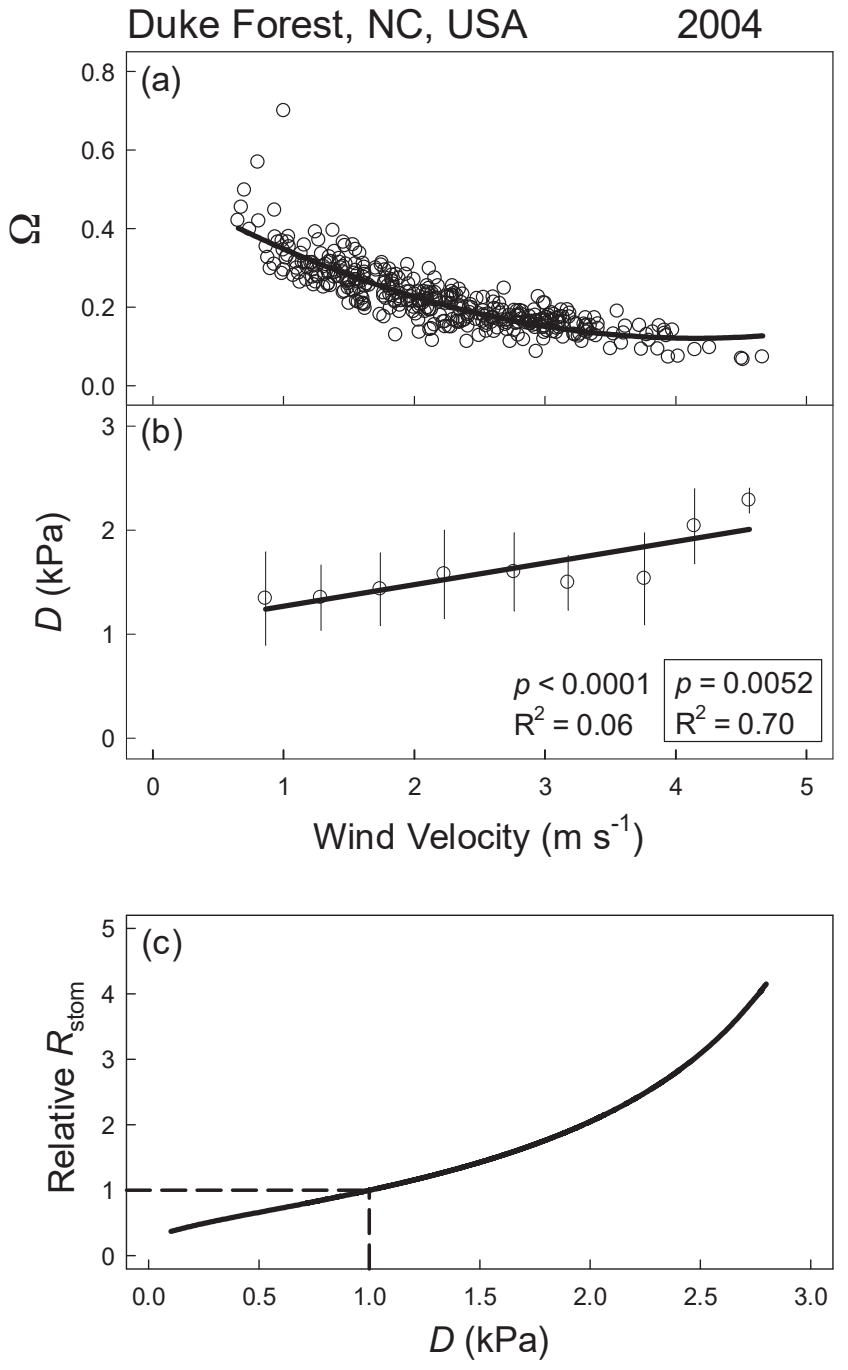

Fig. 6. (a) Responses of the decoupling coefficient $(\Omega)$ to wind velocity $(U)$. (b) Responses of vapor pressure deficit $(D)$ to $U$ (data are mean vapor pressure deficit grouped in $U$ intervals of $0.5 \mathrm{~m} \mathrm{~s}^{-1} ; p$-value and $R^{2}$ within the box were calculated from mean values rather than individual data).(c) The theoretical, hydraulically controlled increase of stomatal resistance $\left(R_{\text {stom }}\right)$ with $D$, normalized by the resistance at $D=1 \mathrm{kPa}$.

sub-canopy) and high LAI $\left(\sim 7 \mathrm{~m}^{2} \mathrm{~m}^{-2}\right)$. Transpiration in a stand with low $\Omega$ value is largely influenced by air humidity and stomatal response rather than available energy (Jarvis and Mcnaughton, 1986; Lindroth, 1993), which in our analysis was set to a limited range (approximately $1500 \leq \mathrm{PAR} \leq 2050 \mu \mathrm{mol} \mathrm{m}^{-2} \mathrm{~s}^{-1}$, and $\left.25 \leq T_{\mathrm{a}} \leq 35^{\circ} \mathrm{C}\right)$. Thus, we assessed further the concurrent variation of $D$ and $R_{\text {stom. }}$.

\subsection{Vapor pressure deficit and its effect on resistances}

$D$ functions as a driving gradient for water vapor exchange through stomata, where carbon assimilation driven by $\mathrm{CO}_{2}$ concentration gradient occurs concurrently. Understanding the effect of $U$ on transpiration is complicated because wind affects not only $R_{\mathrm{A}}$ and $R_{\mathrm{bl}}$, but also $D$, and thus $R_{\text {stom }}$ (Fig. 1 ; Table 1 ; Dixon and Grace, 1984). Gutiérrez et al. (1994) suggested that increased leaf-to-air $D$ at the leaf surface with $U$ generated a positive relationship between normalized $R_{\mathrm{C}}$ and $U$, but evidence of such relationships is rare. In this study, the slight increase in canopy-atmosphere coupling of the stand was sufficient to produce a significant positive relationship ( $p<0.0001$ ) between $U$ and $D$ (Fig. 6b). Grace et al. (1975)

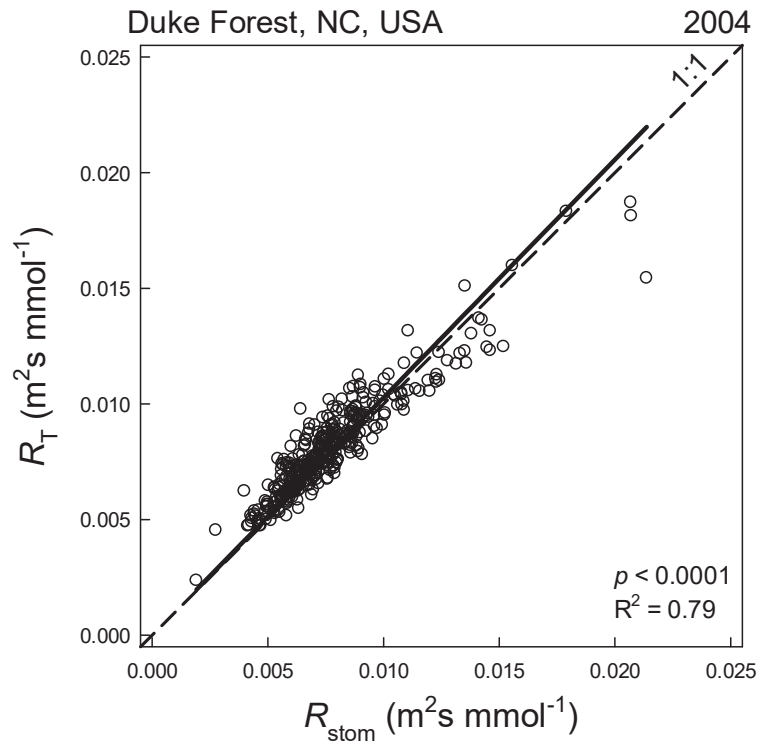

Fig. 7. The relationship between predicted stomatal resistance $\left(R_{\text {stom }}\right)$ and total resistance $\left(R_{\mathrm{T}}\right)$ estimated from sap flux density and associated measurements. $R_{\text {stom }}$ was calculated using equation 10 , with $R_{\text {Sref }}=0.51 \times 10^{-2} \mathrm{~m}^{2}$ (ground area) $\mathrm{s} \mathrm{mmol}^{-1}$ and $m=0.74$. Solid line and dashed line represent a linear fit without intercept and $1: 1$ line.

estimated that as $U$ increased from 0.1 to $1.0 \mathrm{~m} \mathrm{~s}^{-1}$, the effective $D$ at leaf surface increased by $38 \%$. Within the range of our data, the increase of $D$ within the canopy volume averaged $\sim 11 \%$ per $1 \mathrm{~m} \mathrm{~s}^{-1}$ increase in $U$, with greater increases at the lower end. At low $D$, its increase tends to drive higher canopy transpiration (Daudet et al., 1999; Kupper et al., 2011). However, further increases in $D$ lead to stomatal closure (decrease in leaf stomatal conductance) such that transpiration does not increase through the entire range of $D$ commonly observed in temperate forests (Oishi et al., 2010; Oren and Pataki, 2001; Oren et al., 1999; Pataki and Oren, 2003). Phillips and Oren (2001) explained the small variation observed in canopy transpiration of Pinus taeda during periods of daytime $D>0.9 \mathrm{kPa}$ based on compensation of the direct (positive) and indirect (negative) effects of $D$. Indeed, Roberts (1983) suggested the negative feedback between $R_{\text {stom }}$ and $D$ as the reason transpiration is a conservative hydrological process in forests.

More common are studies showing increased $R_{\mathrm{stom}}$ or $R_{\mathrm{C}}$ of broadleaved stands with increased $D$ (Blanken and Black, 2004; Clausnitzer et al., 2011; Granier et al., 2000; Irmak and Mutiibwa, 2010; Jonard et al., 2011; Köstner et al., 1992; Oren and Pataki, 2001; Pataki and Oren, 2003; Schäfer et al., 2000). The response of $R_{\text {stom }}$ to $D$ can be estimated as (Lohammar et al., 1980 ; Oren et al., 1999):

$R_{\text {stom }}=\frac{R_{\text {Sref }}}{1-m \ln (D)}$

where $R_{\text {Sref }}$ is a reference resistance at $D=1 \mathrm{kPa}, m$ is the slope of the relationship between reference conductance $\left(1 / R_{\text {Sref }}\right)$ and the sensitivity of stomatal conductance to $D\left(-d G_{\text {Stom }} / d \ln (D)\right)$. This response is consistent with hydraulic theory and reflects the decreased sensitivity to $D$ of $R_{\text {stom }}$ with increasing $R_{\text {stom }}$ at low $D$ (Katul et al., 2009). We estimated $R_{\text {Sref }}$ and $m$ from coefficients of linear regression between canopy conductance (a reciprocal of $R_{\mathrm{C}}$ ) and the natural $\log$ of $D$. The estimated value of $m, 0.74$, was higher by about $9 \%$ than that estimated in similar forest stands in the area (Oren and Pataki, $2001)$. Based on $R_{\text {Sref }}$ and $m$ we estimated the expected increase of $R_{\text {stom }}$ with $D$ (Fig. 6c). Based on this analysis, as $D$ increases from 0.1 to $3.0 \mathrm{kPa}, R_{\text {stom }}$ should increase about ten-fold, increasing two-fold between 1.0 and $2.0 \mathrm{kPa}$, similar to observation in a 35-year-old oak stand (Granier and Bréda, 1996). 
We examined the expected response of $R_{\text {stom }}$ to $U$ by converting $D$ in equation 13 to $U$ based on the relationship between $D$ and $U$ (from Fig. 6b). Estimated $R_{\text {stom }}$ increased $38 \%$ over the range of $U$ and fell close to or within the $95 \%$ confidence intervals of the relationship between $R_{C}$ and $U$ (Fig. $4 \mathrm{e}$ ). As a result of the small contribution of $R_{\mathrm{A}}$ to $R_{\mathrm{T}}$, the variation of $R_{\mathrm{T}}$ was also highly correlated $(p<0.0001$, $R^{2}=0.79$ ) with the response of $R_{\text {stom }}$ to $D$; the slope was very close to unity, with $R_{\mathrm{T}}$ averaging only $2.8 \%$ higher than the expected values of $R_{\text {stom }}$ (Fig. 7). Thus, we failed to reject $\mathbf{H 3}$, concluding that the direct effect of $D$, acting as a driving gradient for plant transpiration, relative to its indirect effect, inducing stomatal closure (Fig. 1), dominates the response of transpiration to $U$. The average $D$, even in calm wind conditions of less than $<1 \mathrm{~m} \mathrm{~s}^{-1}$, was $>1 \mathrm{kPa}$ in this study, suggesting that much of the time the direct effect of $D$ was offset by $R_{\text {stom }}$ response to $D$, resulting in a constant $E_{\mathrm{C}}$ over the observed range of $U$.

\section{Conclusion}

This study assessed the responses of $J_{S}$ (as a surrogate for transpiration) to $U$ in a mixed hardwood stand under optimal meteorological condition for transpiration based on $T_{\mathrm{a}}$ and $\theta$. $J_{S}$ of the six species were insensitive or weakly responded to increasing $U$; stand-level transpiration appeared not to significantly change with $U$ (H1). The canopy of the broadleaved stand was well-coupled to the atmosphere, and thus had a low $R_{\mathrm{A}}$. Further decrease in $R_{\mathrm{A}}$ with increasing $U$ was readily offset by an increasing $R_{\mathrm{C}}(\mathbf{H 2})$. The increase in $R_{\mathrm{C}}$ was consistent with the theoretical increase in $R_{\text {stom }}$ with $D$ - which in turn increased with $U$ - keeping transpiration constant despite the increase of the driving force $(\mathbf{H 3})$. These results suggest that in similar forests the effect of $U$ on canopy transpiration is negligible. However, due to its effect on $D$ within the canopy and thus $R_{\text {stom }} U$ could have an important influence on $\mathrm{CO}_{2}$ uptake.

\section{Acknowledgments}

This research was supported by the Office of Science (BER) of the US Department of Energy through the Southeastern Regional Center (SERC) of the National Institute for Global Environmental Change (NIGEC), and through Terrestrial Carbon Processes (TCP) program.

\section{References}

Allen, R.G., 2005. Penman-Monteith equation. In: Hillel, D. (Ed.), Encyclopedia of Soils in the Environment. Elsevier/Academic Press, Oxford/Boston, pp. 180-188.

Aphalo, P.J., Jarvis, P.G., 1993. The boundary layer and the apparent responses of stomatal conductance to wind speed and to the mole fractions of $\mathrm{CO}_{2}$ and water vapor in the air. Plant Cell Environ. 16 (7), 771-783.

Avissar, R., Werth, D., 2005. Global hydroclimatological teleconnections resulting from tropical deforestation. J. Hydrometeorol. 6 (2), 134-145.

Bauerle, W.L., Bowden, J.D., 2011. Predicting transpiration response to climate change: insights on physiological and morphological interactions that modulate water exchange from leaves to canopies. Hortscience 46 (2), 163-166.

Bladon, K.D., Silins, U., Landhausser, S.M., Lieffers, V.J., 2006. Differential transpiration by three boreal tree species in response to increased evaporative demand after variable retention harvesting. Agric. For. Meteorol. 138 (1-4), 104-119.

Blanken, P.D., Black, T.A., 2004. The canopy conductance of a boreal aspen forest, Prince Albert National Park, Canada. Hydrol. Processes 18 (9), 1561-1578.

Caldwell, M.M., 1970. Plant gas exchange at high wind speeds. Plant Physiol. 46 (4), 535-537.

Campbell-Clause, J.M., 1998. Stomatal response of grapevines to wind. Aust. J. Exp. Agric. 38 (1), 77-82.

Campbell, G.S., Norman, J.M., 1998. An Introduction to Environmental Biophysics. Springer, New York.

Chapin III, F.S., 2002. Principles of Terrestrial Ecosystem Ecology. Springer, New York.

Chu, C.R., Hsieh, C.I., Wu, S.Y., Phillips, N.G., 2009. Transient response of sap flow to wind speed. J. Exp. Bot. 60 (1), 249-255.

Clausnitzer, F., Kostner, B., Schwarzel, K., Bernhofer, C., 2011. Relationships between canopy transpiration, atmospheric conditions and soil water availability - analyses of long-term sap-flow measurements in an old Norway spruce forest at the Ore Mountains/Germany. Agric. For. Meteorol. 151 (8), 1023-1034.
Daudet, F.A., Le Roux, X., Sinoquet, H., Adam, B., 1999. Wind speed and leaf boundary layer conductance variation within tree crown - consequences on leaf-toatmosphere coupling and tree functions. Agric. For. Meteorol. 97 (3), 171-185.

Dixon, M., Grace, J., 1984. Effect of wind on the transpiration of young trees. Ann. Bot. 53 (6), 811-819.

Grace, J., Malcolm, D.C., Bradbury, I.K., 1975. Effect of wind and humidity on lea diffusive resistance in Sitka spruce seedlings. J. Appl. Ecol. 12 (3), 931-940.

Grace, J., Russel, G., 1982. The effect of wind and a reduced supply of water on the growth and water relations of Festuca-Arundinacea Schreb. Ann. Bot. 49 (2), 217-225.

Granier, A., 1987. Sap flow measurements in Douglas-fir tree trunks by means of a new thermal method. Ann. Sci. For. 44 (1), 1-14.

Granier, A., Bréda, N., 1996. Modelling canopy conductance and stand transpiration of an oak forest from sap flow measurements. Ann. Sci. For. 53 (2-3), 537-546.

Granier, A., Loustau, D., Bréda, N., 2000. A generic model of forest canopy conductance dependent on climate, soil water availability and leaf area index. Ann. For. Sci. 57 (8), 755-765.

Gutiérrez, M.V., Meinzer,F.C.,Grantz, D.A., 1994. Regulation of transpiration in coffee hedgerows - covariation of environmental variables and apparent responses of stomata to wind and humidity. Plant Cell Environ. 17 (12), 1305-1313.

Harlow, W.M., Harrar, E.S., Hardin, J.W., White, F.M., 1996. Textbook of Dendrology. McGraw-Hill Series in Forest Resources. McGraw-Hill, New York

Hinckley, T.M., Brooks, J.R., Čermák, J., Ceulemans, R., Kučera, J., Meinzer, F.C., Roberts, D.A., 1994. Water flux in a hybrid poplar stand. Tree Physiol. 14 (7-9), 1005-1018.

Holmgren, B., Ovhed, M., Karlsson, P.S., 1996. Measuring and modeling stomatal and aerodynamic conductances of Mountain birch: implications for treeline dynamics. Arct. Alp. Res. 28 (4), 425-434.

Irmak, S., Mutiibwa, D., 2010. On the dynamics of canopy resistance: generalized linear estimation and relationships with primary micrometeorological variables. Water Resour. Res. 46, W08526.

Jarvis, P.G., 1976. The interpretation of the variations in leaf water potential and stomatal conductance found in canopies in the field. Philos. Trans. R. Soc. Lond. Ser. B: Biol. Sci. 273 (927), 593-610.

Jarvis, P.G., Mcnaughton, K.G., 1986. Stomatal control of transpiration - scaling up from leaf to region. Adv. Ecol. Res. 15, 1-49.

Jonard, F., Andre, F., Ponette, Q., Vincke, C., Jonard, M., 2011. Sap flux density and stomatal conductance of European beech and common oak trees in pure and mixed stands during the summer drought of 2003. J. Hydrol. 409 (1-2), $371-381$

Jones, H.G., 1992. Plants and Microclimate: A Quantitative Approach to Environmental Plant Physiology. Cambridge University Press, Cambridge, England, New York, NY, USA.

Juang, J.Y., Porporato, A., Stoy, P.C., Siqueira, M.S., Oishi, A.C., Detto, M., Kim, H.S. Katul, G., 2007. Hydrologic and atmospheric controls on initiation of convective precipitation events. Water Resour. Res. 43 (3.).

Katsoulas, N., Baille, A., Kittas, C., 2007. Leaf boundary layer conductance in ventilated greenhouses: an experimental approach. Agric. For. Meteorol. 144 (3-4) 180-192.

Katul, G.G., Palmroth, S., Oren, R., 2009. Leaf stomatal responses to vapour pressure deficit under current and $\mathrm{CO}_{2}$-enriched atmosphere explained by the economics of gas exchange. Plant Cell Environ. 32 (8), 968-979.

Kelliher, F.M., Leuning, R., Raupach, M.R., Schulze, E.D., 1995. Maximum conductances for evaporation from global vegetation types. Agric. For. Meteorol. 73 (1-2), 1-16.

Kelliher, F.M., Leuning, R., Schulze, E.D., 1993. Evaporation and canopy characteristics of coniferous forests and grasslands. Oecologia 95 (2), 153-163.

Kim, H.S., Oren, R., Hinckley, T.M., 2008. Actual and potential transpiration and carbon assimilation in an irrigated poplar plantation. Tree Physiol. 28 (4), 559-577.

Kitaya, Y., Shibuya, T., Yoshida, M., Kiyota, M., 2004. Effects of air velocity on photosynthesis of plant canopies under elevated $\mathrm{CO}_{2}$ levels in a plant culture system. Adv. Space Res. 34 (7), 1466-1469.

Komatsu, H., Kang, Y.H., Kume, T., Yoshifuji, N., Hotta, N., 2006. Transpiration from a Cryptomeria japonica plantation, part 1: aerodynamic control of transpiration. Hydrol. Processes 20 (6), 1309-1320.

Konings, A.G., Dekker, S.C., Rietkerk, M., Katul, G.G., 2011. Drought sensitivity of patterned vegetation determined by rainfall-land surface feedbacks. J. Geophys. Res.-Biogeo. 116.

Köstner, B.M.M., Schulze, E.-D., Kelliher, F.M., Hollinger, D.Y., Byers, J.N., Hunt, J.E., McSeveny, T.M., Meserth, R., Weir, P.L., 1992. Transpiration and canopy conductance in a pristine broad-leaved forest of Nothofagus - an analysis of xylem sap flow and eddy-correlation measurements. Oecologia 91 (3), 350-359.

Kumagai, T., Saitoh, T.M., Sato, Y., Morooka, T., Manfroi, O.J., Kuraji, K., Suzuki, M., 2004. Transpiration, canopy conductance and the decoupling coefficient of a lowland mixed dipterocarp forest in Sarawak, Borneo: dry spell effects. J. Hydrol. 287 (1-4), 237-251

Kupper, P., Sõber, J., Sellin, A., Lõhmus, K., Tullus, A., Räim, O., Lubenets, K., Tulva, I., Uri, V., Zobel, M., Kull, O., Sõber, A., 2011. An experimental facility for free air humidity manipulation (FAHM) can alter water flux through deciduous tree canopy. Environ. Exp. Bot. 72 (3), 432-438.

Launiainen, S., Katul, G.G., Kolari, P., Vesala, T., Hari, P., 2011. Empirical and optima stomatal controls on leaf and ecosystem level $\mathrm{CO}_{2}$ and $\mathrm{H}_{2} \mathrm{O}$ exchange rates. Agric For. Meteorol. 151 (12), 1672-1689.

Lei, H., Zhi-Shan, Z., Xin-Rong, L., 2010. Sap flow of Artemisia ordosica and the influence of environmental factors in a evegetated desert area: Tengger Desert, China. Hydrol. Processes 24, 1248-1253. 
Lindroth, A., 1993. Aerodynamic and canopy resistance of short-rotation forest in relation to leaf area index and climate. Boundary-Layer Meteorol. 66 (3), 265-279.

Lohammar, T., Larsson, S., Linder, S., Falk, S.O., 1980. FAST: simulation models of gaseous exchange in Scots pine. Ecol. Bull. 32, 505-523.

Lu, P., Urban, L., Zhao, P., 2004. Granier's thermal dissipation probe (TDP) method for measuring sap flow in trees: theory and practice. Acta Bot. Sin. 46 (6), 631-646.

Morris, J., Mann, L., Collopy, J., 1998. Transpiration and canopy conductance in a eucalypt plantation using shallow saline groundwater. Tree Physiol. 18 (8-9), 547-555.

Novel, P.S., 2005. Physicochemical and Environmental Plant Physiology. Elsevier, Burlington.

Oishi, A.C., Oren, R., Novick, K.A., Palmroth, S., Katul, G.G., 2010. Interannual invariability of forest evapotranspiration and its consequence to water flow downstream. Ecosystems 13 (3), 421-436.

Oishi, A.C., Oren, R., Stoy, P.C., 2008. Estimating components of forest evapotranspiration: a footprint approach for scaling sap flux measurement. Agric. For. Meteorol. 148 (11), 1719-1732.

Oren, R., Pataki, D.E., 2001. Transpiration in response to variation in microclimate and soil moisture in southeastern deciduous forests. Oecologia 127 (4), 549-559.

Oren, R., Phillips, N., Katul, G., Ewers, B.E., Pataki, D.E., 1998. Scaling xylem sap flux and soil water balance and calculating variance: a method for partitioning water flux in forests. Ann. Sci. For. 55 (1-2), 191-216.

Oren, R., Sperry, J.S., Katul, G.G., Pataki, D.E., Ewers, B.E., Phillips, N., Schäfer, K.V.R., 1999. Survey and synthesis of intra- and interspecific variation in stomatal sensitivity to vapour pressure deficit. Plant Cell Environ. 22 (12), 1515-1526.

Pataki, D.E., Oren, R., 2003. Species differences in stomatal control of water loss at the canopy scale in a mature bottomland deciduous forest. Adv. Water Resour. 26 (12), 1267-1278.

Pereira, D.D., de Mello, C.R., da Silva, A.M., Yanagi, S.D.M., 2010. Evapotranspiration and estimation of aerodynamic and stomatal conductance in a fragment of Atlantic Forest in Mantiqueira Range region, MG. Cerne 16 (1), 32-40.

Perry, D.A., 2008. Forest Ecosystems. Johns Hopkins University Press, Baltimore.

Phillips, N., Oren, R., 2001. Intra- and inter-annual variation in transpiration of a pine forest. Ecol. Appl. 11 (2), 385-396.

Roberts, J., 1983. Forest transpiration - a conservative hydrological process. J. Hydrol. $66(1-4), 133-141$.

Running, S.W., Hunt, E.R., 1993. Generalization of a Forest Ecosystem Process Model for Other Biomes, BIOME-BGC, and an Application for Global-Scale Models. Scaling Physiological Processes: Leaf to Globe. Academic Press, San Diego.

Schäfer, K.V.R., Oren, R., Ellsworth, D.S., Lai, C., Herrick, J.D., Finzi, A.C., Richter, D.D., Katul, G.G., 2003. Exposure to an enriched $\mathrm{CO}_{2}$ atmosphere alters carbon assimilation and allocation in a pine forest ecosystem. Global Change Biol. 9 (10), 1378-1400.
Schäfer, K.V.R., Oren, R., Tenhunen, J.D., 2000. The effect of tree height on crown level stomatal conductance. Plant Cell Environ. 23 (4), 365-375.

Schuepp, P.H., 1993. Tansley review no. 59 leaf boundary-layers. New Phytol. 125 (3), 477-507.

Stewart, J.B., 1988. Modeling surface conductance of pine forest. Agric. For. Meteorol. 43 (1), 19-35.

Stokes, V.J., Morecroft, M.D., Morison, J.I.L., 2006. Boundary layer conductance for contrasting leaf shapes in a deciduous broadleaved forest canopy. Agric. For. Meteorol. 139 (1-2), 40-54.

Stoy, P.C., Katul, G.G., Siqueira, M.B.S., Juang, J.Y., McCarthy, H.R., Kim, H.S., Oishi, A.C., Oren, R., 2005. Variability in net ecosystem exchange from hourly to interannual time scales at adjacent pine and hardwood forests: a wavelet analysis. Tree Physiol. 25 (7), 887-902.

Stoy, P.C., Katul, G.G., Siqueira, M.B.S., Juang, J.Y., Novick, K.A., McCarthy, H.R., Oishi, A.C., Uebelherr, J.M., Kim, H.S., Oren, R., 2006. Separating the effects of climate and vegetation on evapotranspiration along a successional chronosequence in the southeastern US. Global Change Biol. 12 (11), 2115-2135.

Tatarinov, F.A., Kucera, J., Cienciala, E., 2005. The analysis of physical background of tree sap flow measurement based on thermal methods. Meas. Sci. Technol. 16 (5), 1157-1169.

Taylor, P.J., Nuberg, I.K., Hatton, T.J., 2001. Enhanced transpiration in response to wind effects at the edge of a blue gum (Eucalyptus globulus) plantation. Tree Physiol. 21 (6), 403-408.

Ward, E.J., Oren, R., Sigurdsson, B.D., Jarvis, P.G., Linder, S., 2008. Fertilization effects on mean stomatal conductance are mediated through changes in the hydraulic attributes of mature Norway spruce trees. Tree Physiol. 28 (4), 579-596.

Waring, R.H., 2007. Forest Ecosystems: Analysis at Multiple Scales. Elsevier/Academic Press, Amsterdam, Boston.

Wilson, K.B., Baldocchi, D.D., Aubinet, M., Berbigier, P., Bernhofer, C., Dolman, H., Falge, E., Field, C., Goldstein, A., Granier, A., Grelle, A., Halldor, T., Hollinger, D. Katul, G., Law, B.E., Lindroth, A., Meyers, T., Moncrieff, J., Monson, R., Oechel, W., Tenhunen, J., Valentini, R., Verma, S., Vesala, T., Wofsy, S., 2002. Energy partitioning between latent and sensible heat flux during the warm season at FLUXNET sites. Water Resour. Res. 38, 1294-1304.

Wullschleger, S.D., Childs, K.W., King, A.W., Hanson, P.J., 2011. A model of heat transfer in sapwood and implications for sap flux density measurements using thermal dissipation probes. Tree Physiol. 31 (6), 669-679.

Xu, M., Chang, C.-P., Fu, C., Qi, Y., Robock, A., Robinson, D., Zhang, H., 2006. Steady decline of east Asian monsoon winds, 1969-2000: evidence from direct ground measurements of wind speed. J. Geophys. Res. -Atmos. 111 (D24).

Zalesny, R.S., Wiese, A.H., Bauer, E.O., Riemenschneider, D.E., 2006. Sapflow of hybrid poplar (Populus nigra L. $\times$ P-maximowiczii A. Henry 'NM6') during phytoremediation of landfill leachate. Biomass Bioenergy 30 (8-9), 784L 793. 
Table 1

Field studies that have investigated relationships between transpiration (or sap flux) and wind velocity.

\begin{tabular}{|c|c|c|c|c|c|c|}
\hline Correlation & Site description (species) & $\begin{array}{l}\text { Wind velocity } \\
\left(\mathrm{m} \mathrm{s}^{-1}\right)\end{array}$ & Tree stage(age in years) & $\mathrm{LAI}^{\mathrm{a}}$ & $\begin{array}{l}\operatorname{SLA}^{\mathrm{b}} \\
\left(\mathrm{cm}^{2} \mathrm{~g}^{-1}\right)\end{array}$ & Source \\
\hline \multirow[t]{5}{*}{ Positive } & $\begin{array}{l}\text { Hardwood, South Australia } \\
\text { (Eucalyptus globulus) }\end{array}$ & - & Young (7) & - & $62-192^{\mathrm{d}}$ & Taylor et al. (2001) \\
\hline & $\begin{array}{l}\text { Boreal mixedwood, Alberta, } \\
\text { Canada } \\
\text { (Picea glauca, P. balsamifera, } \\
\text { Betula papyrifera) }\end{array}$ & $0-2$ & Mature (45-50) & - & - & Bladon et al. (2006) \\
\hline & $\begin{array}{l}\text { Shrub, Tengger desert, China } \\
\text { (Artemisia ordosica) }\end{array}$ & - & $(10)$ & $0.5-0.9$ & - & Lei et al. (2010) \\
\hline & $\begin{array}{l}\text { Temperate hardwood, Estonia } \\
\text { (B. pendula, } P \text {. tremula }+P \text {. } \\
\text { tremuloides }^{\mathrm{C}} \text { ) }\end{array}$ & $0-4$ & Seedling (1) & - & - & Kupper et al. (2011) \\
\hline & $\begin{array}{l}\text { Temperate hardwood, China } \\
\text { (Populus alba) }\end{array}$ & $0-0.6$ & Young (7-10) & $0-2$ & $100-120^{\mathrm{d}}$ & Xu et al. (2006) \\
\hline \multirow[t]{2}{*}{ Negative } & $\begin{array}{l}\text { Shrub, island of Kauai, USA } \\
\text { (Coffea arabica L.) }\end{array}$ & $1-3$ & $(1-5.3)$ & $0.7-6.7$ & - & Gutiérrez et al. (1994) \\
\hline & $\begin{array}{l}\text { Hardwood, Wisconsin, USA } \\
\left(P . \text { nigra } \text { P. maximowiczii }{ }^{\mathrm{C}}\right)\end{array}$ & $0-4.5$ & Young & - & - & Zalesny et al. (2006) \\
\hline \multirow[t]{4}{*}{ Weak or none } & $\begin{array}{l}\text { Hardwood, Plauzat, France } \\
\text { (Juglans regia) }\end{array}$ & $0-4$ & Mature (20) & 9 & $82-398^{\mathrm{d}}$ & Daudet et al. (1999) \\
\hline & $\begin{array}{l}\text { Softwood, Chiba, Japan } \\
\text { (Cryptomeria japonica) }\end{array}$ & $0-1.5$ & Young (8) & 3.7 & - & Komatsu et al. (2006) \\
\hline & $\begin{array}{l}\text { Crop, Nebraska, USA } \\
\text { (Zea mays L.) }\end{array}$ & $0-7$ & - & $1-5$ & - & Irmak and Mutiibwa (2010) \\
\hline & $\begin{array}{l}\text { Temperate hardwood, Durham, } \\
\text { USA } \\
\text { (Liriodendron tulipifera, } \\
\text { Liquidambar styraciflua, Carya } \\
\text { tomentosa, Quercus alba, Q. } \\
\text { michauxii, Q. phellos) }\end{array}$ & $0.8-4.7$ & Mature (80-100) & 7.03 & $102-174$ & This study \\
\hline
\end{tabular}

Resistance to transpiration $\left(R_{\mathrm{T}}\right)$ can be partitioned into two serial components, bulk surface resistance $\left(R_{\text {sur }}\right)$ and aerodynamic resistance $\left(R_{\mathrm{A}}\right)$,

$R_{\mathrm{T}}=R_{\mathrm{sur}}+R_{\mathrm{A}}$

both of which depend on leaf physiology, canopy architecture and the atmospheric conditions above and within the canopy (Jones, 1992; Kumagai et al., 2004). $R_{\text {sur }}$ is generally attributed to canopy resistance $\left(R_{\mathrm{C}}\right)$ and soil (or forest floor) resistance $\left(R_{\text {soil }}\right)$ acting in parallel (Allen, 2005).

$R_{\text {sur }}=\frac{R_{\mathrm{C}} R_{\text {soil }}}{R_{\mathrm{C}}+R_{\text {soil }}}$

Soil evaporation is minor under high canopy leaf area, making $R_{\mathrm{C}}$ effectively equivalent to $R_{\text {sur }}$ when leaf area index (LAI) is greater than 3 (Kelliher et al., 1995; Waring, 2007). $R_{\mathrm{C}}$ can be expressed as a combination of stomatal resistance $\left(R_{\text {stom }}\right)$ and leaf boundary layer resistance $\left(R_{\mathrm{bl}}\right)$ in series (Aphalo and Jarvis, 1993):

$R_{\mathrm{C}}=R_{\mathrm{stom}}+R_{\mathrm{bl}}$

$R_{\text {stom }}$ reflects complex physiological responses of stomata to variation in atmospheric conditions, such as light availability, air temperature $\left(T_{\mathrm{a}}\right)$, humidity, $\mathrm{CO}_{2}$ concentration (Jarvis, 1976). $R_{\mathrm{bl}}$ is the resistance to vapor transfer within the air layer near leaf surface, and can be affected by wind velocity $(U)$, leaf shape, leaf size, edge characteristics, and surface structure (Schuepp, 1993; Stokes et al., 2006). $R_{\mathrm{bl}}$ is generally much smaller than $R_{\text {stom }}$ unless leaf size is large or $U$ is low (Aphalo and Jarvis, 1993; Schuepp, 1993).

Over time scales in which soil moisture and plant hydraulic properties (e.g. soil-to-leaf path-length, sapwood-to-leaf area ratio, hydraulic conductivity) can be considered invariable, $R_{\mathrm{C}}$ is largely determined by $R_{\text {stom. Jarvis (1976) described stomatal conductance }}$ (the inverse of $R_{\text {stom }}$ ) as a form of multiplicative function with photon flux density, vapor pressure deficit $(D), T_{\mathrm{a}}$, ambient $\mathrm{CO}_{2}$ concentration, and leaf water potential. Many formulations for $R_{\mathrm{stom}}$, ranging from empirical to theoretically-based functions have been proposed and used (Holmgren et al., 1996; Jonard et al., 2011; Launiainen et al., 2011; Pataki and Oren, 2003; Stewart, 1988), but except for allowing interactions among the controlling variables (Ward et al., 2008), this approach remained fundamentally unaltered. The other primary component of $R_{\mathrm{T}}, R_{\mathrm{A}}$, is determined by the physical conditions above and within the canopy, such as $U$, atmospheric stability, and canopy structure (Kumagai et al., 2004; Lindroth, 1993; Morris et al., 1998). Although estimates of $R_{\mathrm{A}}$ in forests are usually small relative to $R_{\mathrm{C}}$, reflected in that $R_{\mathrm{A}}$ is neglected in some biosphere-atmosphere exchange models (Granier et al., 2000; Kelliher et al., 1993; Köstner et al., 1992), few studies have actually quantified the effect of $U$ on $R_{\mathrm{A}}$ and, in-turn, on transpiration (Table 1 ). The results of these studies are inconclusive: some studies observed increased transpiration with $U$ (Chu et al., 2009; Grace and Russel, 1982; Kitaya et al., 2004); others observed a decline (Caldwell, 1970; Campbell-Clause, 1998; Dixon and Grace, 1984; Gutiérrez et al., 1994), or found transpiration to be insensitive to $U$ (Komatsu et al., 2006).

Here we analyze the effect of $U$ on transpiration through measurements and by quantifying the response to $U$ of estimated resistances in the water vapor pathway, focusing on the reduced expression:

$R_{\mathrm{T}}=R_{\mathrm{A}}+R_{\mathrm{bl}}+R_{\mathrm{stom}}$

Many of the studies on transpiration response to $U$ were performed in wind tunnels (Caldwell, 1970; Chu et al., 2009; Dixon and Grace, 1984; Grace and Russel, 1982; Kitaya et al., 2004). However, results of wind tunnel experiments may differ from those of field experiments because they do not account for the effect of neighboring crowns (shelter effect) on the coupling between stomata 


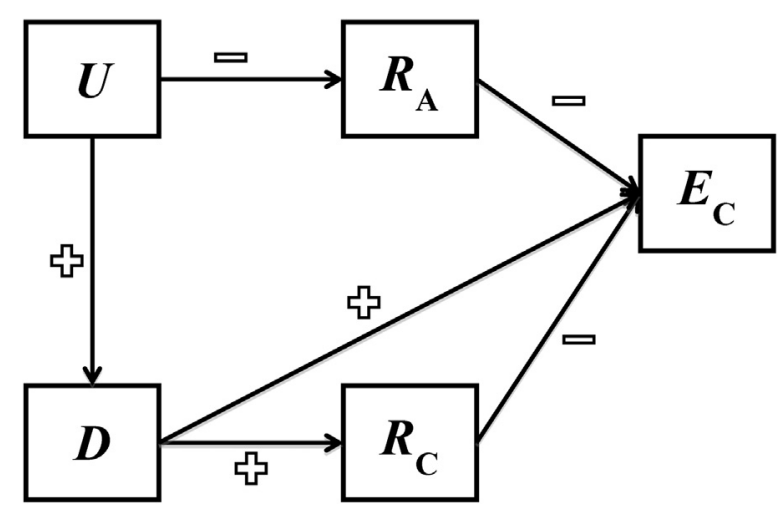

Fig. 1. Diagram showing the effect of wind velocity, $U$, on transpiration, $E_{\mathrm{C}}$ in a bigleaf framework. The sign represents the relationship between the two parameters at the arrow tip and tail ( $D$ - vapor pressure deficit; $R_{\mathrm{A}}$ - aerodynamic resistance; $R_{\mathrm{C}}$ - canopy resistance). For example, an increase in $U$ results in a decrease in $R_{\mathrm{A}}$ because of the negative relationship between $U$ and $R_{\mathrm{A}}$ and, in turn, the decrease in $R_{\mathrm{A}}$ leads to an increase in $E_{\mathrm{C}}$ because of the negative relationship between $R_{\mathrm{A}}$ and E.

and atmosphere in forest stands. In situ experiments were performed to overcome the limits of wind tunnels, but most have focused on crops and other small statured canopies; eight of the ten in situ studies we found were made on such canopies (Table 1). The response of these canopies to $U$ may differ from that of forests canopies which tend to be rougher, and thus better coupled to the atmosphere (Jones, 1992). Furthermore, the aerodynamic roughness of forest canopies depends on tree height, stand density, tree size distribution, and LAI, all of which change with stand age (Chapin, 2002; Perry, 2008). Thus, if $R_{\mathrm{A}}$ is actually large, it would require quantification for each combination of stand characteristics before estimating biosphere-atmosphere exchanges.

As LAI increases, $R_{C}$ decreases, improving the canopyatmosphere coupling (Granier and Bréda, 1996; Granier et al., 2000; Katsoulas et al., 2007), yet the increase in canopy leaf area may impede air movement, increasing $R_{\mathrm{A}}$ while decreasing $D$ within the canopy. At a given canopy LAI, as $U$ increases, the accompanying decrease of $R_{\mathrm{A}}$ allows for frequent replacement of moist canopy air with dry air from aloft, potentially driving more transpiration, yet the drier air may force stomatal closure and increase $R_{\text {stom }}$ (Fig. 1). Thus, the effect of $U$ on tree and canopy transpiration represents a balance among interacting processes and may not be simple to predict. Transpiration could therefore decrease with increasing $U$ if $R_{C}$ increases as a result of stomatal response to $D$, overwhelming both the decrease of $R_{\mathrm{A}}$ as well as the increase of $D$, the driving force for transpiration.

The goals of this study were to improve understanding of the effect of $U$ on transpiration. We assessed the response to $U$ of sap flux density $\left(J_{S}\right)$, a proxy of transpiration, of six co-occurring species, ranging in shade tolerance, leaf dimensions and leaf clumping, in a mature broadleaved deciduous forest, testing the following hypotheses: (H1) transpiration will increase with $U$ as a result of the combination of direct and indirect effects on resistances and forces above and within the canopy; $(\mathbf{H 2}) R_{\mathrm{A}}$ has a small effect on $R_{\mathrm{T}}$ meaning that $R_{\mathrm{T}}$ is dominated by the components of $R_{\text {sur }}$ (mostly $R_{\mathrm{C}}$, in-turn dominated by $R_{\mathrm{stom}}$ ); thus (H3) the response of $E_{\mathrm{C}}$ to $U$ will be determined by the effects of increases in $D$ with $U$ on $R_{\text {stom }}$ and the increase in the driving force, rather than by the direct effect of $U$ on $R_{\mathrm{A}}$ and $R_{\mathrm{bl}}$.

\section{Materials and methods}

\subsection{Site description and data collection}

The study was conducted at the Duke Forest hardwood site, North Carolina $\left(36^{\circ} 58^{\prime} \mathrm{N}, 79^{\circ} 05^{\prime} \mathrm{W}\right.$ ) from 2002 to 2005 . The maximum tree age of the hardwood stand is $\sim 100$ years. Mean and maximum canopy heights of the stand are $25 \mathrm{~m}$ and $35 \mathrm{~m}$, respectively (Pataki and Oren, 2003). A total of 40 trees of the six dominant species, yellow (tulip) poplar (Liriodendron tulipifera), sweetgum (Liquidambar styraciflua), hickory (Carya tomentosa), white oak (Quercus alba), swamp chestnut oak (Q. michauxii), and willow oak (Q. phellos), were selected for sap flux measurement (Table 2). $J_{S}$ was measured with $20 \mathrm{~mm}$ long Granier-type heat dissipation sensors (Granier, 1987). The Granier-type technique has a potential to produce bias of $J_{S}$ due to its sensitivity to physical factors including thermal conductivity of sapwood, temperature gradients within sapwood, and variation in $J_{S}$ with sapwood depth (Tatarinov et al., 2005; Wullschleger et al., 2011). However, using the same data, Oishi et al. (2010) showed that $J_{S}$ produced similar estimates of latent heat flux when properly scaled to the site's eddy-covariance footprint. The measurement depths varied from $0-20$ to $0-60 \mathrm{~mm}$ based on the expected depth of sapwood; sensors generating values at least two standard deviations apart from values collected by others in the same species and measurement depth were excluded to avoid potential underestimation caused by excessive penetration into heartwood (Lu et al., 2004).

$T_{\mathrm{a}}$ and relative humidity were measured at two-thirds of the mean canopy height with a temperature/RH probe (HMP35C, Campbell Scientific, Logan, UT, USA), and used to calculate $D$ (Campbell and Norman, 1998). Photosynthetically active radiation (PAR) was measured above the canopy using a quantum sensor (LI190SA, LI-COR, Lincoln, NE, USA). Volumetric soil moisture $(\theta)$ was measured in 12 locations, at $5-10 \mathrm{~cm}$ and $20-25 \mathrm{~cm}$ in each location, using ThetaProbe sensors (ML2x, Delta-T Devices, Cambridge, UK). $U$ was measured with a tri-axial sonic anemometer installed above the canopy at $39.8 \mathrm{~m}$ (CSAT3, Campbell Scientific, Logan, UT,

Table 2

Characteristics of sampled trees at the Duke Forest hardwood site. Standard deviations are shown in parentheses.

\begin{tabular}{|c|c|c|c|c|c|c|c|}
\hline Species & $\mathrm{DBH}^{\mathrm{a}}$ & $\mathrm{LAD}^{\mathrm{b}}$ & $J_{\mathrm{S}}{ }^{\mathrm{c}}$ & $A_{\mathrm{S}}^{\mathrm{d}}$ & SLA $^{\mathrm{e}}$ & $d^{\mathrm{f}}$ & Number of trees \\
\hline L. tulipifera & $39.3(14.96)$ & 0.017 & $42.36(15.21)$ & 2.37 & 161.8 & 8.3 & 10 \\
\hline L. styraciflua & $36.58(12.16)$ & 0.020 & $29.44(13.10)$ & 2.09 & 102.4 & 8.1 & 10 \\
\hline Other diffuse porous & - & - & - & 1.48 & 173.3 & - & - \\
\hline C. tomentosa & $34.12(20.86)$ & 0.062 & $36.32(15.30)$ & 2.11 & 131.9 & 4.7 & 5 \\
\hline Q. alba & $32.34(18.46)$ & 0.018 & $42.30(12.61)$ & 0.52 & 112.2 & 5.4 & 5 \\
\hline Q. michauxii & $33.68(16.80)$ & 0.014 & $37.55(10.40)$ & 0.59 & 128.9 & 6.8 & 5 \\
\hline Q. phellos & $49.48(9.02)$ & 0.003 & $43.88(10.28)$ & 0.27 & 101.9 & 1.1 & 5 \\
\hline Other ring porous & - & - & - & 0.60 & - & - & - \\
\hline
\end{tabular}

a Diameter at breast height $(\mathrm{cm})$.

b Leaf area density $\left(\mathrm{m}^{2} \mathrm{~m}^{-3}\right)$.

c verage sap flux density $\left(\mathrm{g} \mathrm{H}_{2} \mathrm{O} \mathrm{m}^{-2} \mathrm{~s}^{-1}\right)$ from selected data.

d Sapwood area $\left(\mathrm{cm}^{2} \mathrm{~m}^{-2}\right)$ weighed based on radial profiles of $J_{\mathrm{S}}$ (Oishi et al., 2008).

e Specific leaf area $\left(\mathrm{cm}^{2} \mathrm{~g}^{-1}\right)$.

${ }^{f}$ Leaf characteristic dimension (cm; Harlow et al., 1996). 


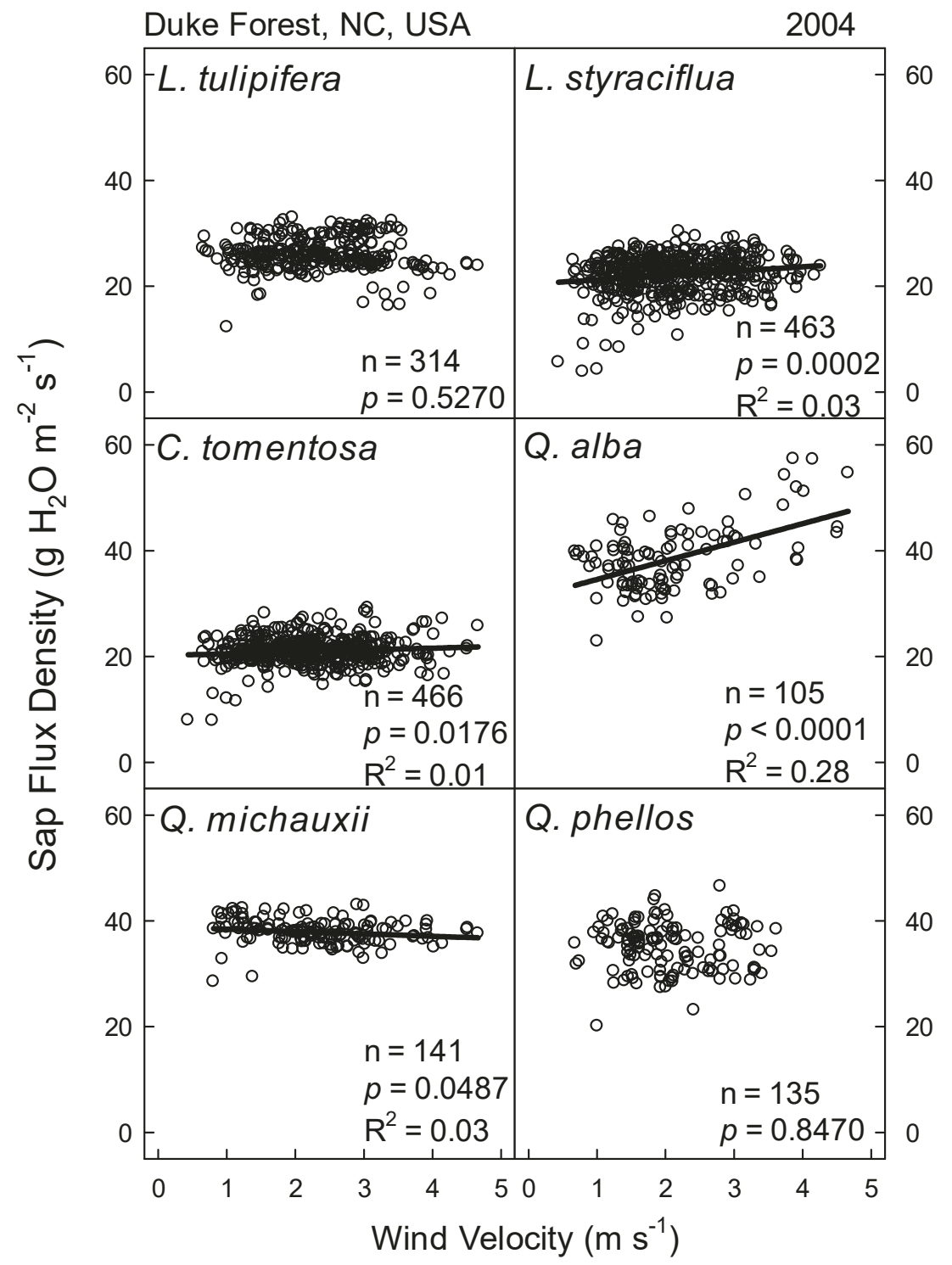

Fig. 2. The effect of wind velocity on sap flux density of six species in the Duke Forest hardwood site. Solid lines represent significant relationships at $p<0.05$.

USA). More details on the site and measurements are given in previous publications on the stand (Oishi et al., 2008; Pataki and Oren, 2003; Stoy et al., 2006). Thirty-minute averages of all the measurements were stored on data loggers (CR23X, Campbell Scientific, Logan, UT, USA).

\subsection{Data preparation}

To minimize the effects of meteorological variables other than $U$, we selected data during times in which leaf area index is reasonably stable (DOY 120-275, excluding the short period of fast leaf expansion and the long period of leaf abscission and shedding) and conditions where transpiration is not likely limited by $T_{\mathrm{a}}\left(\geq 25^{\circ} \mathrm{C}\right)$ and $\theta\left(\geq 0.2 \mathrm{~m}^{3} \mathrm{~m}^{-3}\right)$. Data under these conditions were further partitioned to four ranges of light (PAR, at $500 \mu \mathrm{mol} \mathrm{m}^{-2} \mathrm{~s}^{-1}$ up to $1500 \mu \mathrm{mol} \mathrm{m}^{-2} \mathrm{~s}^{-1}$, and one class for data under $P A R \geq 1500 \mu \mathrm{mol} \mathrm{m}^{-2} \mathrm{~s}^{-1}$, on which we concentrated most of the analyses for reasons that will become clear later).

$J_{S}$ varies greatly among sensors (Granier, 1987). Typically, before estimating species or stand scale transpiration, missing data is gap-filled to avoid the effect on the average $J_{S}$ of single sensors dropping in and out of the data set. However, we chose a conservative approach, relying on only operating sensors, selecting the largest number of sensors for each species resulting in at least 3000 half-hourly, species level averages over the study period, all produced by the same three to five sensors. The $2003 J_{S}$ data of Q. michauxii were excluded from analysis because the values were unstable. When calculating stand-scale $E_{C}$, missing average $J_{S}$ of any species ( $\sim 54 \%$ of potential values) resulted in missing half-hourly stand-scale $E_{\mathrm{C}}$. To gap-fill the missing average $J_{S}$, a power function $\left(y=a+b x^{n}\right)$ was fitted among species when average $J_{S}$ of at least three species were available ( $\sim 64 \%$ of the time under the selected conditions). If the data of more than three species at a given halfhour were missing, the data were neither gap-filled nor used for $E_{C}$ calculation; otherwise, missing data of a species were gap-filled using data of another species with the best fit in terms of $R^{2}$ value. Approximately $50 \%$ of the missing data were gap-filled. The performance of the gap-filling procedure was evaluated by comparing the data unused in developing the gap-filling functions ( $\sim 36 \%$ of the time, when data for only one or two species were available) and estimates based on the function developed for each species. The estimated values were well fitted with observed ones $\left(R^{2}>0.89\right.$; slope ranged from 0.88 to 1.10 ). 


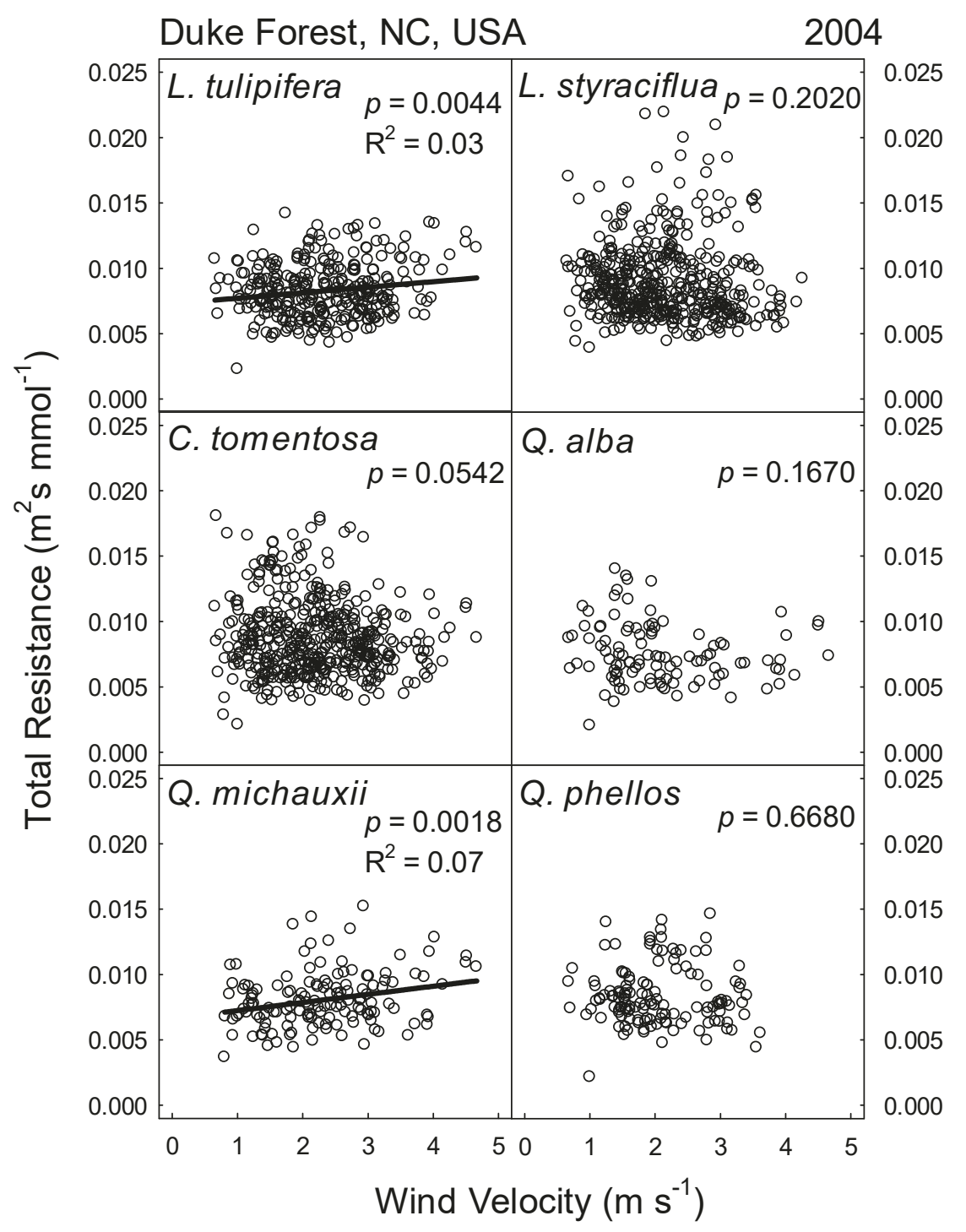

Fig. 3. The relationship between wind velocity and total resistance. Solid lines represent significant relationships at $p<0.05$.

$R_{\mathrm{A}}$ in the air layer above the canopy surface was estimated by Monin-Obukhov similarity theory (Campbell and Norman, 1998):

$R_{\mathrm{A}}=\frac{\left[\ln \left((z-d) / z_{\mathrm{om}}\right)+\Psi_{\mathrm{M}}\right]\left[\ln \left((z-d) / z_{\mathrm{oh}}\right)+\Psi_{\mathrm{H}}\right]}{k^{2} \hat{\rho} U}$

$$
\times\left(\mathrm{m}^{2} \mathrm{~s} \mathrm{mmol}^{-1}\right)
$$

$\Psi_{\mathrm{H}}= \begin{cases}6 \ln (1+\zeta), & \text { for stable flow } \\ -2 \ln \left[\frac{1+(1-16 \zeta)^{1 / 2}}{2}\right], & \text { for unstable flow }\end{cases}$

$\Psi_{\mathrm{M}}= \begin{cases}\Psi_{\mathrm{H}}, & \text { for stable flow } \\ 0.6 \Psi_{\mathrm{H}}, & \text { for unstable flow }\end{cases}$

where $\hat{\rho}$ is the molar density of air $\left(\mathrm{mmol} \mathrm{m}^{-3}\right), k(=0.4)$ is the von Karman constant, $U$ is the wind velocity $\left(\mathrm{m} \mathrm{s}^{-1}\right), z$ is the height of measured wind velocity $(\mathrm{m}), d$ is the zero plane displacement $(\mathrm{m})$, $z_{\text {om }}$ is the momentum roughness length $(\mathrm{m}), z_{\mathrm{oh}}$ is the scalar roughness length for heat transfer $(\mathrm{m}), \Psi_{\mathrm{M}}$ and $\Psi_{\mathrm{H}}$ are the profile diabatic correction factors for buoyant instability, $\zeta$ is the atmospheric stability. The parameters $d, z_{\mathrm{om}}$, and $z_{\mathrm{oh}}$ were taken as fixed values, $0.67,0.1$, and 0.02 of the canopy height in this study, making the effect of the surface roughness length constant during the growing season. A $10 \%$ variation of each of the three parameters changed the maximum of calculated values of $R_{\mathrm{A}}$ by $2.8,1.8$, and $1.7 \%$, supporting the assumption of constant parameters.

$R_{\mathrm{C}}$ was obtained by subtracting $R_{\mathrm{A}}$ from the total resistance $\left(R_{\mathrm{T}}\right)$, which was calculated from a rearranged Penman-Monteith equation after Blanken and Black (2004):

$R_{\mathrm{T}}=\frac{s}{\gamma} \beta R_{\mathrm{A}}+\frac{\rho c_{\mathrm{p}} D}{\hat{\rho} \gamma \lambda E_{\mathrm{C}}}\left(\mathrm{m}^{2} \mathrm{~s} \mathrm{mmol}^{-1}\right)$

where $s$ is the slope of the saturation vapor pressure with $T_{\mathrm{a}}$ $\left(\mathrm{kPa} \mathrm{K}^{-1}\right), \gamma$ is the psychrometric constant $\left(\mathrm{kPa} \mathrm{K}^{-1}\right), \beta$ is the Bowen ratio (ratio of sensible to latent heat fluxes), $\rho$ is the density of air $\left(\mathrm{kg} \mathrm{m}^{-3}\right), c_{\mathrm{p}}$ is the specific heat of $\operatorname{air}\left(\mathrm{J} \mathrm{kg}^{-1} \mathrm{~K}^{-1}\right), D$ is the vapor pressure deficit $(\mathrm{kPa}), \lambda$ is the latent heat of vaporization $\left(\mathrm{Jg}^{-1}\right)$, and $E_{\mathrm{C}}$ is the canopy transpiration $\left(\mathrm{g} \mathrm{H}_{2} \mathrm{O} \mathrm{m}^{-2}\right.$ (ground area) $\mathrm{s}^{-1}$ ). Typical values of $\beta$ for temperate forests (lower in deciduous than in conifer forests) ranged from 0.4 to 0.8 (Novel, 2005; Wilson et al., 2002). Since a change of $\beta$ by 0.1 within the range resulted in only $2.5 \%$ difference in $R_{\mathrm{T}}$ under the selected conditions in this study, $\beta$ was 
assumed to be constant (0.5). $E_{C}$ was estimated with $J_{S}$ from outer sensors (depth of $0-20 \mathrm{~mm} ; \mathrm{g} \mathrm{H}_{2} \mathrm{O} \mathrm{m}^{-2}$ (sapwood area) $\mathrm{s}^{-1}$ ) and cross-sectional sapwood area per unit ground area $\left(A_{S} ; \mathrm{cm}^{2} \mathrm{~m}^{-2}\right)$ weighed using radial profiles of $J_{S}$. The weighed $A_{S}$ of each species was obtained from allometric relationship between diameter at breast height and sapwood area (Oishi et al., 2008, 2010).

To assess the importance of $R_{\mathrm{bl}}$ in this stand, species mean $R_{\mathrm{bl}}$ values were calculated using an equation for the resistance of vapor transport in forced convection (Campbell and Norman, 1998), which dominates over free convection in this canopy (Stoy et al., 2006):

$R_{\mathrm{bl}}=\frac{v^{1 / 6}}{0.664 \hat{\rho} D_{\mathrm{v}}^{2 / 3}} \sqrt{\frac{d_{\mathrm{l}}}{u}}=0.0068 \sqrt{\frac{d_{\mathrm{l}}}{u}}\left(\mathrm{~m}^{2} \mathrm{~s}^{1 / 2} \mathrm{mmol}^{-1}\right)$

where $v$ is the kinematic viscosity of air $\left(\mathrm{m}^{2} \mathrm{~s}^{-1}\right), D_{\mathrm{v}}$ is the molecular diffusivity of water vapor in air $\left(\mathrm{m}^{2} \mathrm{~s}^{-1}\right), d_{1}$ is the leaf characteristic dimensions (0.011-0.083 m; Table 2), and $u$ is the vertically averaged $U$ within canopy $\left(\mathrm{m} \mathrm{s}^{-1}\right)$. A constant value of $0.0068 \mathrm{~m}^{2} \mathrm{~s}^{1 / 2} \mathrm{mmol}^{-1}$ was used for $v^{1 / 6}\left(0.664 \hat{\rho} D_{\mathrm{v}}^{2 / 3}\right)^{-1}$ (Campbell and Norman, 1998). $u$ was estimated based on $U$ profiles within canopy and LAI profile when canopy leaf area was at its stable seasonal plateau (DOY 154):

$u=\frac{\sum_{h=1}^{H} U(h) \operatorname{LAI}(h)}{\sum_{h=1}^{H} \operatorname{LAI}(h)}$

where $U(h)$ and $\operatorname{LAI}(h)$ are $U$ and LAI at a height $h$ within canopy, and $H$ is the canopy height $(\mathrm{m})$. The $U$ profiles were calculated as (Campbell and Norman, 1998):

$U(h)=u_{0} e^{a((h / H)-1)}$

where $u_{0}$ is the $U$ at the top of the canopy and $a$ is an attenuation coefficient (assumed to be 2.5). The LAI profile was estimated from measurements at $\sim 2 \mathrm{~m}$ intervals from 1 to $45 \mathrm{~m}$ along a tower using an optical plant canopy analyzer (LAI-2000, LI-COR, Lincoln, NE, USA; Stoy et al., 2005).

Also, to understand the coupling between the air within and above the canopy volume, the decoupling coefficient for the canopy $(\Omega)$ was considered. In this study $\Omega$ was calculated using Jarvis and Mcnaughton (1986):

$\Omega=\frac{(s / \gamma)+1}{(s / \gamma)+1+\left(R_{\mathrm{C}} / R_{\mathrm{A}}\right)}$

$\Omega$ approaches zero when the ratio $R_{\mathrm{C}} / R_{\mathrm{A}}$ approaches infinity, a condition of perfect coupling between the air in the canopy volume and the bulk air above the canopy (i.e. very efficient mass and energy exchange), resulting in essentially identical $T_{\mathrm{a}}$ and humidity in these two locations. If $R_{\mathrm{A}}$ is much larger than $R_{\mathrm{C}}, \Omega$ approaches one, reflecting the isolation of the air in the canopy volume from that aloft.

\section{Results and discussion}

\subsection{Sap flux density}

We first examined the relationship between $U$ and $J_{S}$. We used a subset of the available data to minimize the effects of other variables including light, temperature, and soil water. The means (and ranges) of $T_{\mathrm{a}}$, PAR, $\theta, D$, and $U$ of the selected data were $29.0 \quad(25.0-35.1)^{\circ} \mathrm{C}, \quad 1662 \quad(1500-2047) \mu \mathrm{mol} \mathrm{m}^{-2} \mathrm{~s}^{-1}$,

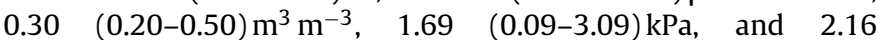
$(0.44-5.09) \mathrm{m} \mathrm{s}^{-1}$, respectively. Although the size of the subset is only $5.3 \%$ of total daytime of the stable LAI period (but see below), the range of $U$ includes $98.3 \%$ of the range of $U$ during daytime hours of the growing season above this stand. The average
JS of L. tulipifera, L. styraciflua, C. tomentosa, Q. alba, Q. michauxii, and $Q$. phellos after the filtering were 26.0, 22.1, 20.9, 38.5, 37.8, and $35.0 \mathrm{~g} \mathrm{H}_{2} \mathrm{O} \mathrm{m}^{-2}$ (sapwood area) $\mathrm{s}^{-1}$, respectively.

Fig. 2 shows the relationship between 30 min average $J_{S}$ of the six species and $U$ during the growing season. Over the wide range of $U, J_{S}$ of $L$. tulipifera and $Q$. phellos did not change significantly. For $L$. styraciflua, C. tomentosa, $Q$. alba, and $Q$. michauxii, the relationships were weak $\left(R^{2}=0.01-0.28\right)$ and inconsistent in sign. The sensitivity of $J_{S}$ to $U$ can be influenced by different leaf size among species because specific leaf dimension (i.e. leaf width in the direction of the wind) changes the leaf boundary layer thickness (Campbell and Norman, 1998). However, no effect of leaf size on the $J_{S}-U$ sensitivity was observed among species $(p=0.796)$.

Observations of the relationship between $U$ and sap flux (or tree transpiration) were diverse. For example, increasing $U$ by up to $2 \mathrm{~m} \mathrm{~s}^{-1}$ by partially harvesting a boreal stand composed of Picea glauca, P. balsamifera, and Butula papyrifera increased transpiration per unit leaf area (Bladon et al., 2006), but sap flux of hybrid poplar (Populus nigra L. $\times$ P. maximowiczii A. Henry) was negatively correlated to $U$ (Zalesny et al., 2006). Komatsu et al. (2006) found no difference of sap flux of Cryptomeria japonica under a given $D$ at all $U>0.7 \mathrm{~m} \mathrm{~s}^{-1}$. In a study of 7-year-old Eucalyptus globulus the ratio of sap flux of edge trees to that of trees far from the edge increased with $U$ when $R_{C}$ of edge trees was sufficiently low to cause leaf temperature to equal $T_{\mathrm{a}}$ (Taylor et al., 2001). Similarly at the individual crown scale, simulated transpiration of 20-year-old Juglans regia foliage increased slightly as $U$ increased from 1 to $5 \mathrm{~m} \mathrm{~s}^{-1}$ in shaded leaves but was insensitive to $U$ in sunlit leaves that had higher leaf temperature than $T_{\mathrm{a}}$ (Daudet et al., 1999). The results of these studies demonstrate the complex effect $U$ can have on stand transpiration.

\subsection{Total, aerodynamic, and canopy resistance}

In order to examine how $U$ affected resistances, we first calculated $R_{\mathrm{T}}$ for each species from its $J_{\mathrm{S}}$ and $A_{\mathrm{S}}$, as if the stand was entirely composed by that species (Fig. 3). The mean $R_{\mathrm{T}}$ values of each species (L. tulipifera, L. styraciflua, C. tomentosa, $Q$. alba, $Q$. michauxii, and $Q$. phellos) were $0.83 \times 10^{-2}, 0.89 \times 10^{-2}$, $0.87 \times 10^{-2}, 0.75 \times 10^{-2}, 0.81 \times 10^{-2}$, and $0.83 \times 10^{-2} \mathrm{~m}^{2}$ (ground area) $\mathrm{s} \mathrm{mmol}{ }^{-1}$, respectively. $R_{\mathrm{T}}$ weakly increased with $U$ for two species in the stand (L. tulipifera and Q. michauxii; Fig. 3).

Stand-level $R_{\mathrm{T}}$ based on the actual species composition was calculated using sap flux-scaled canopy transpiration $\left(E_{\mathrm{C}}\right) . E_{\mathrm{C}}$ was unrelated to $U$ in three PAR intervals $(0-500,500-1000$, and $\left.1000-1500 \mu \mathrm{mol} \mathrm{m}^{-2} \mathrm{~s}^{-1}\right)$ when analyzed along the entire range of $U$ found in each interval ( $p=0.0746,0.3710$, and 0.0707; Fig. 4a). In the highest PAR interval $\left(\geq 1500 \mu \mathrm{mol} \mathrm{m}^{-2} \mathrm{~s}^{-1}\right)$, a weak positive relationship was observed between $E_{C}$ and $U\left(p=0.0069, R^{2}=0.02\right)$. However, the increase of $E_{\mathrm{C}}$ associated with $\sim 7$-fold increase of $U$ was only $6.5 \%$. Thus, we must reject H1: under most conditions, stand transpiration did not increase with $U$.

Although $R_{\mathrm{T}}$ increased with $U$ for two species, the relationship between stand-level $R_{\mathrm{T}}$ and $U$ was not significant ( $p=0.3650$; Fig. 4b). Because of the observed lack of or limited sensitivity of $E_{C}$ to $U$ in any PAR range, we concentrate our analyses on only the one set of conditions in which no environmental variable was limiting, thus reducing the variation in the calculated resistances. The direct effect of $U$ on water transport through the air layer above the canopy is reflected in $R_{\mathrm{A}}$. The average $R_{\mathrm{A}}$ of this stand was $4.62 \times 10^{-4} \mathrm{~m}^{2}$ (ground area) $\mathrm{smmol}^{-1}$, within the range of values from other broadleaved forest stands (Köstner et al., 1992; Kumagai et al., 2004; Lindroth, 1993; Pereira et al., 2010). The estimated values of $R_{\mathrm{A}}$ over the canopy decreased from $1.31 \times 10^{-3}$ to $1.95 \times 10^{-4} \mathrm{~m}^{2}$ (ground area) $\mathrm{smmol}^{-1}$ as $U$ increased from $\sim 0.7$ to $\sim 4.7 \mathrm{~m} \mathrm{~s}^{-1}$ (Fig. $4 \mathrm{c}$ ). However, consistent with $\mathbf{H 2}, R_{\mathrm{A}}$ was a 
Duke Forest, NC, USA

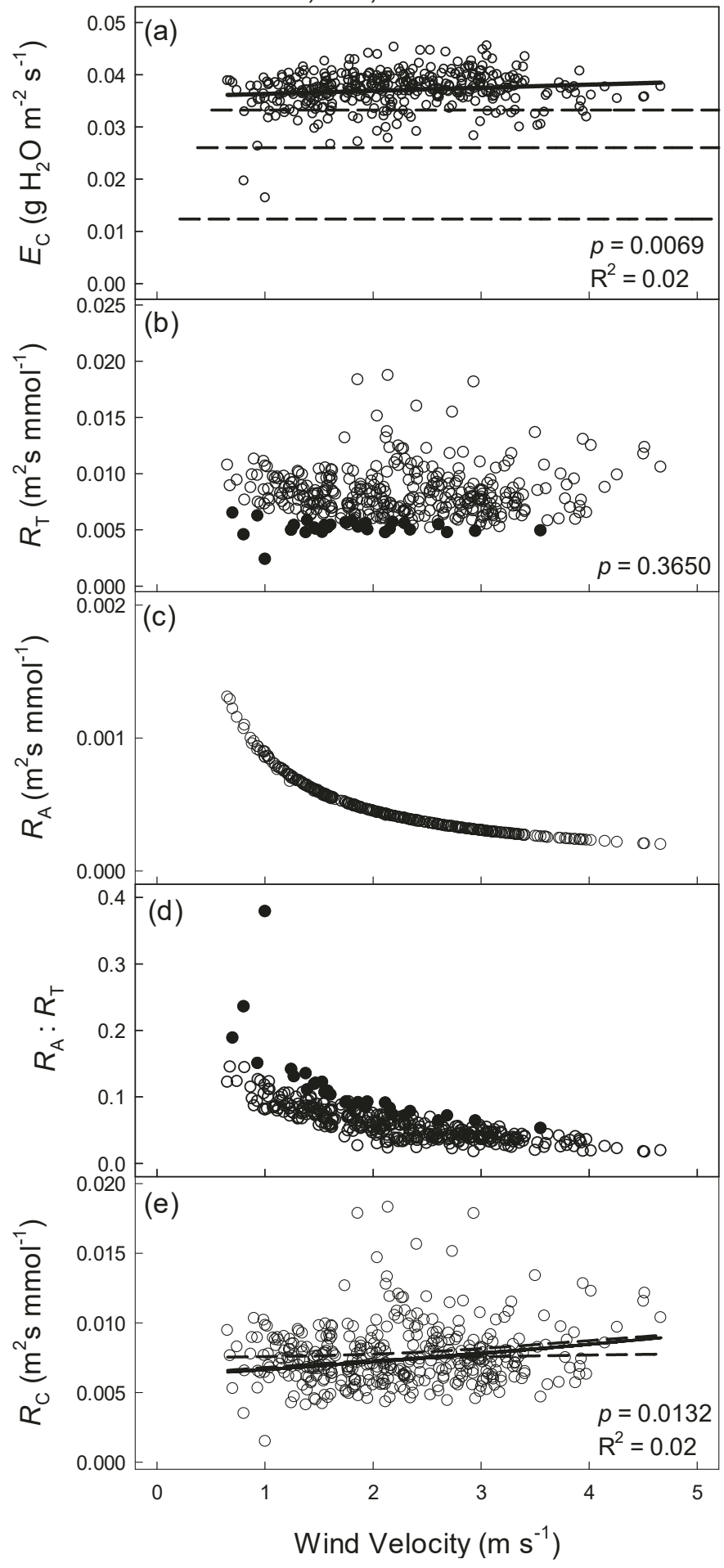

Fig. 4. Changes in stand-level transpiration and resistances with increasing wind velocity $(U)$. (a) Canopy transpiration $\left(E_{\mathrm{C}}\right)$; dashed lines from the bottom up represent light conditions of $500 \mu \mathrm{mol} \mathrm{m}^{-2} \mathrm{~s}^{-1}$ intervals from 0 to $1500 \mu \mathrm{mol} \mathrm{m}^{-2} \mathrm{~s}^{-1}$, while the data points represent conditions of $>1500 \mu \mathrm{mol} \mathrm{m}^{-2} \mathrm{~s}^{-1}$. Only one PAR interval ( $>1500 \mu \mathrm{mol} \mathrm{m}^{-2} \mathrm{~s}^{-1}$ ) showed significant yet very weak correlation (solid line). (b) total resistance $\left(R_{\mathrm{T}}\right)$; filled circles represent $R_{\mathrm{T}}$ when vapor pressure deficit $(D)$ is low ( $<1 \mathrm{kPa})$, (c) aerodynamic resistance $\left(R_{\mathrm{A}}\right)$, (d) proportion of $R_{\mathrm{A}}$ to $R_{\mathrm{T}}$; filled circles represent the proportion when $D$ is low $(<1 \mathrm{kPa})$, and (e) canopy resistance $\left(R_{\mathrm{C}}\right)$ with $95 \%$ confidence intervals for individual estimates (dashed lines) and expected $R_{\text {stom }}$ based on the relationship between $R_{\text {stom }}$ and vapor pressure deficit $(D)$, and between $D$ and $U$ (solid line; see text).
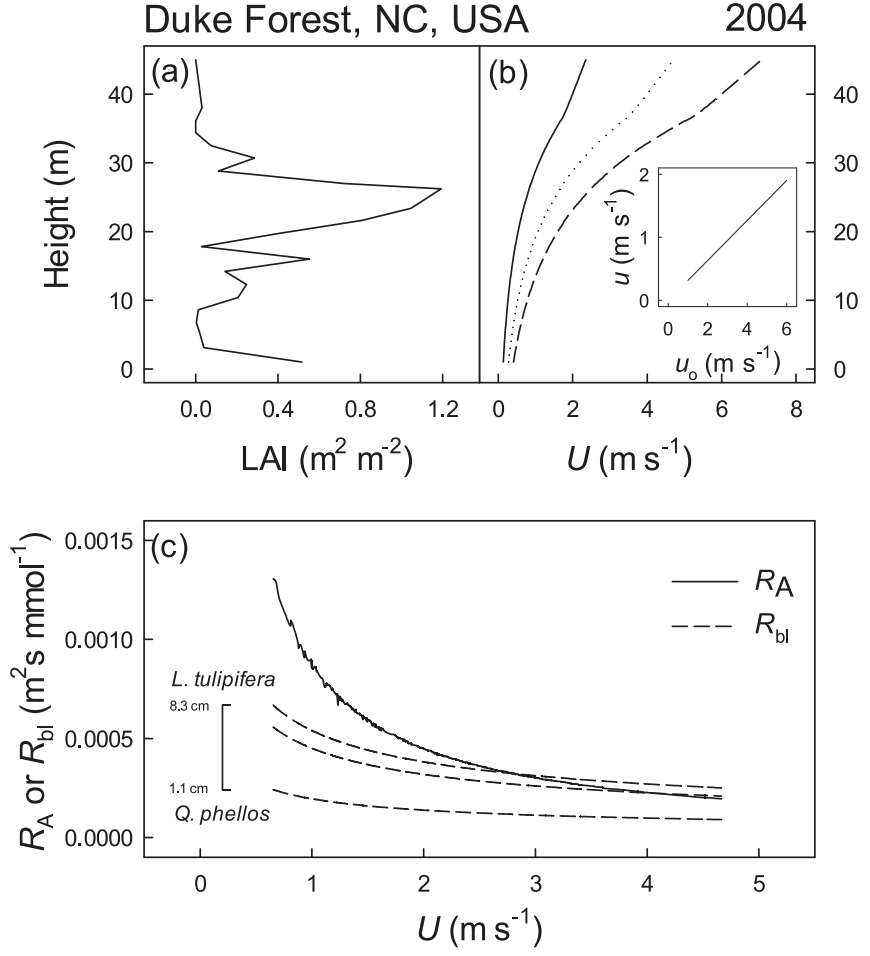

Fig. 5. (a) Leaf area index (LAI) profile (DOY 154). (b) Calculated wind velocity $(U)$ profiles above and within the canopy when $U$ at measurement height $(39.8 \mathrm{~m})$ are 2 (solid line), 4 (dotted line), and $6 \mathrm{~m} \mathrm{~s}^{-1}$ (dashed line). Inset figure shows the relationship between $U$ above canopy $\left(u_{0}\right)$ and average $U$ within canopy weighted by leaf area profile $(u)$. (c) Aerodynamic resistance $\left(R_{\mathrm{A}}\right.$; solid line) and leaf boundary layer resistance ( $R_{\mathrm{bl}}$; dashed lines) estimated using $U$ and leaf characteristic dimensions of the six species, ranged from $1.1 \mathrm{~cm}$ for $Q$. phellos to $8.6 \mathrm{~cm}$ for $L$. tulipifera (see Table 2); the dashed lines from the top represent $R_{\mathrm{bl}}$ estimates of $L$. tulipifera, weighed average, and Q. phellos.

relatively small component of $R_{\mathrm{T}}$, decreasing from $15 \%$ to $1.6 \%$ with increasing $U$ except three half-hourly values with $18.8,23.5$ and $37.8 \%$ due to exceptionally low $D(0.10,0.31$ and $0.97 \mathrm{kPa}$; Fig. $4 \mathrm{~d})$. When $D$ was low, $R_{\mathrm{T}}$ was generally lower under all $U$ condition, and thus the ratio of $R_{\mathrm{A}}$ to $R_{\mathrm{T}}$ increased somewhat with decreasing $D$ (see Fig. $4 \mathrm{~b}$ and d).

$R_{\mathrm{C}}$, calculated by subtracting $R_{\mathrm{A}}$ from $R_{\mathrm{T}}$, increased with $U$ in the stand $\left(p=0.0132 ; R^{2}=0.2\right.$; Fig. $\left.4 \mathrm{e}\right)$. The mean $R_{\mathrm{C}}$ of the stand was $7.61 \times 10^{-3} \mathrm{~m}^{2}$ (ground area) $\mathrm{s} \mathrm{mmol}^{-1}$, similar to values observed in other broadleaved forest stands (Blanken and Black, 2004; Hinckley et al., 1994). In a Coffea arabica plantation, $R_{\mathrm{C}}$ normalized by PAR also increased with increasing $U$ from 1 to $2.5 \mathrm{~m} \mathrm{~s}^{-1}$ (Gutiérrez et al., 1994), as it did, albeit weakly, in a Zea mays field (Irmak and Mutiibwa, 2010).

We assessed the contribution of $R_{\mathrm{bl}}$ to $R_{\mathrm{C}}$ modeling the wind velocity profile down the canopy based on leaf-area profile and characteristic leaf dimensions (Fig. 5a and b). The maximum values of $R_{\mathrm{bl}}$ of the six species ranged from $2.76 \times 10^{-4}$ to $7.64 \times 10^{-4} \mathrm{~m}^{2}$ (ground area) $\mathrm{s} \mathrm{mmol}{ }^{-1}$, an order of magnitude smaller than $R_{\mathrm{C}}$ over much of the range of $U$ in this stand (Figs. $4 \mathrm{e}$ and $5 \mathrm{c}$ ). Indeed, $R_{\mathrm{bl}}$ was less than half of $R_{\mathrm{A}}$ at low $U$, becoming similar to $R_{\mathrm{A}}$ only at very high $U$ when the sum of both resistances was a very small component of the total. Thus, $R_{\mathrm{stom}}$ is much greater than $R_{\mathrm{bl}}$ and can be assumed equivalent to $R_{\mathrm{C}}$. We test this assumption when we address $\mathbf{H} \mathbf{3}$ in the last section.

The small absolute decrease of $R_{\mathrm{A}}$ with increasing $U$, and the low ratio of $R_{\mathrm{A}}$ to $R_{\mathrm{T}}$ at our stand indicate that the stand was generally well-coupled to the atmosphere (mean $\Omega=0.22$; Fig. 6a) despite its high tree density ( $\sim 866$ total trees per hectare), extensive vertical distribution of foliage $(\sim 685$ of $\sim 866$ trees were in the 

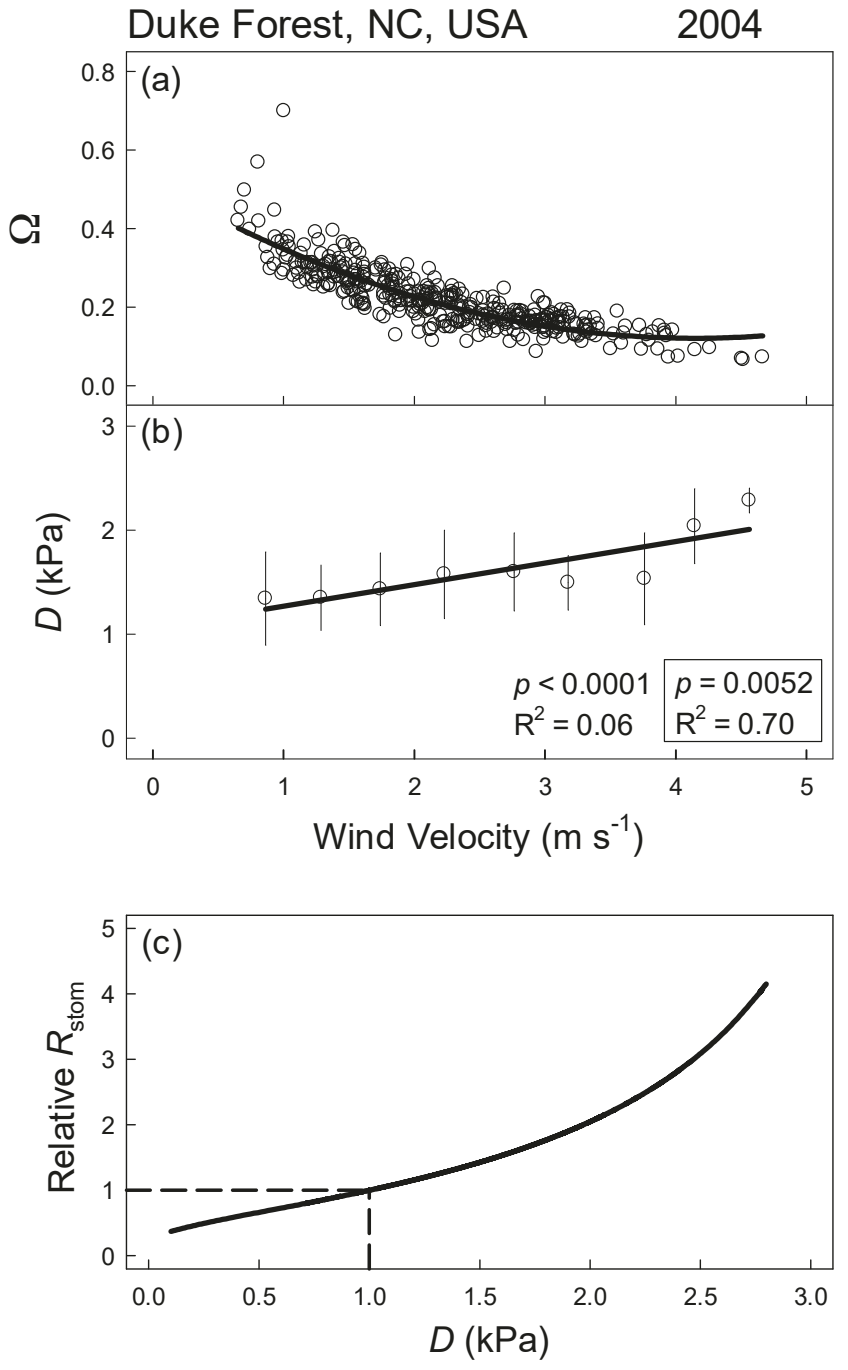

Fig. 6. (a) Responses of the decoupling coefficient $(\Omega)$ to wind velocity $(U)$. (b) Responses of vapor pressure deficit $(D)$ to $U$ (data are mean vapor pressure deficit grouped in $U$ intervals of $0.5 \mathrm{~m} \mathrm{~s}^{-1} ; p$-value and $R^{2}$ within the box were calculated from mean values rather than individual data).(c) The theoretical, hydraulically controlled increase of stomatal resistance $\left(R_{\text {stom }}\right)$ with $D$, normalized by the resistance at $D=1 \mathrm{kPa}$.

sub-canopy) and high LAI $\left(\sim 7 \mathrm{~m}^{2} \mathrm{~m}^{-2}\right)$. Transpiration in a stand with low $\Omega$ value is largely influenced by air humidity and stomatal response rather than available energy (Jarvis and Mcnaughton, 1986; Lindroth, 1993), which in our analysis was set to a limited range (approximately $1500 \leq \mathrm{PAR} \leq 2050 \mu \mathrm{mol} \mathrm{m}^{-2} \mathrm{~s}^{-1}$, and $\left.25 \leq T_{\mathrm{a}} \leq 35^{\circ} \mathrm{C}\right)$. Thus, we assessed further the concurrent variation of $D$ and $R_{\text {stom. }}$.

\subsection{Vapor pressure deficit and its effect on resistances}

$D$ functions as a driving gradient for water vapor exchange through stomata, where carbon assimilation driven by $\mathrm{CO}_{2}$ concentration gradient occurs concurrently. Understanding the effect of $U$ on transpiration is complicated because wind affects not only $R_{\mathrm{A}}$ and $R_{\mathrm{bl}}$, but also $D$, and thus $R_{\text {stom }}$ (Fig. 1 ; Table 1 ; Dixon and Grace, 1984). Gutiérrez et al. (1994) suggested that increased leaf-to-air $D$ at the leaf surface with $U$ generated a positive relationship between normalized $R_{\mathrm{C}}$ and $U$, but evidence of such relationships is rare. In this study, the slight increase in canopy-atmosphere coupling of the stand was sufficient to produce a significant positive relationship ( $p<0.0001$ ) between $U$ and $D$ (Fig. 6b). Grace et al. (1975)

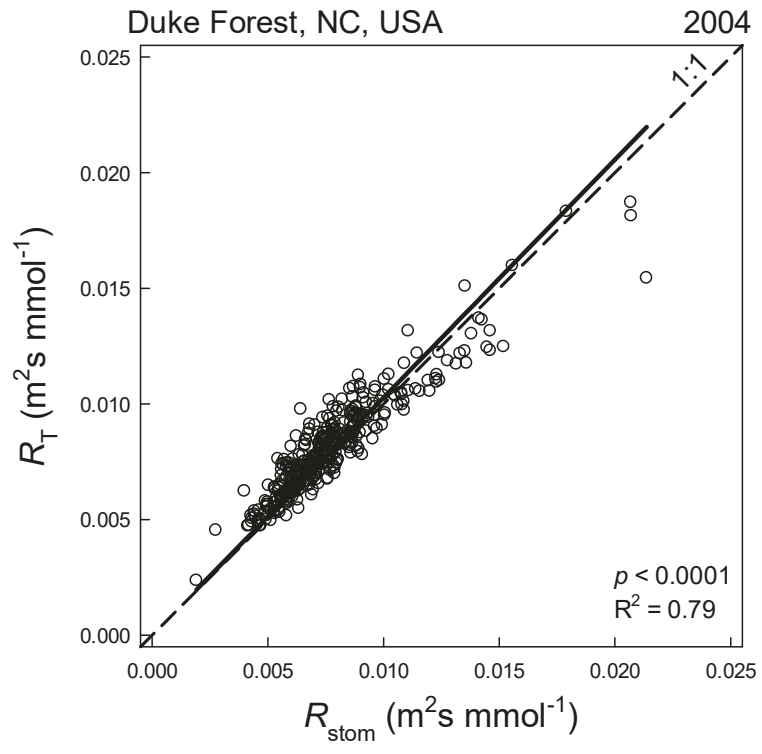

Fig. 7. The relationship between predicted stomatal resistance $\left(R_{\text {stom }}\right)$ and total resistance $\left(R_{\mathrm{T}}\right)$ estimated from sap flux density and associated measurements. $R_{\text {stom }}$ was calculated using equation 10 , with $R_{\text {Sref }}=0.51 \times 10^{-2} \mathrm{~m}^{2}$ (ground area) $\mathrm{s} \mathrm{mmol}^{-1}$ and $m=0.74$. Solid line and dashed line represent a linear fit without intercept and $1: 1$ line.

estimated that as $U$ increased from 0.1 to $1.0 \mathrm{~m} \mathrm{~s}^{-1}$, the effective $D$ at leaf surface increased by $38 \%$. Within the range of our data, the increase of $D$ within the canopy volume averaged $\sim 11 \%$ per $1 \mathrm{~m} \mathrm{~s}^{-1}$ increase in $U$, with greater increases at the lower end. At low $D$, its increase tends to drive higher canopy transpiration (Daudet et al., 1999; Kupper et al., 2011). However, further increases in $D$ lead to stomatal closure (decrease in leaf stomatal conductance) such that transpiration does not increase through the entire range of $D$ commonly observed in temperate forests (Oishi et al., 2010; Oren and Pataki, 2001; Oren et al., 1999; Pataki and Oren, 2003). Phillips and Oren (2001) explained the small variation observed in canopy transpiration of Pinus taeda during periods of daytime $D>0.9 \mathrm{kPa}$ based on compensation of the direct (positive) and indirect (negative) effects of $D$. Indeed, Roberts (1983) suggested the negative feedback between $R_{\text {stom }}$ and $D$ as the reason transpiration is a conservative hydrological process in forests.

More common are studies showing increased $R_{\mathrm{stom}}$ or $R_{\mathrm{C}}$ of broadleaved stands with increased $D$ (Blanken and Black, 2004; Clausnitzer et al., 2011; Granier et al., 2000; Irmak and Mutiibwa, 2010; Jonard et al., 2011; Köstner et al., 1992; Oren and Pataki, 2001; Pataki and Oren, 2003; Schäfer et al., 2000). The response of $R_{\text {stom }}$ to $D$ can be estimated as (Lohammar et al., 1980; Oren et al., 1999):

$R_{\text {stom }}=\frac{R_{\text {Sref }}}{1-m \ln (D)}$

where $R_{\text {Sref }}$ is a reference resistance at $D=1 \mathrm{kPa}, m$ is the slope of the relationship between reference conductance $\left(1 / R_{\text {Sref }}\right)$ and the sensitivity of stomatal conductance to $D\left(-d G_{\text {Stom }} / d \ln (D)\right)$. This response is consistent with hydraulic theory and reflects the decreased sensitivity to $D$ of $R_{\text {stom }}$ with increasing $R_{\text {stom }}$ at low $D$ (Katul et al., 2009). We estimated $R_{\text {Sref }}$ and $m$ from coefficients of linear regression between canopy conductance (a reciprocal of $R_{\mathrm{C}}$ ) and the natural $\log$ of $D$. The estimated value of $m, 0.74$, was higher by about $9 \%$ than that estimated in similar forest stands in the area (Oren and Pataki, $2001)$. Based on $R_{\text {Sref }}$ and $m$ we estimated the expected increase of $R_{\text {stom }}$ with $D$ (Fig. 6c). Based on this analysis, as $D$ increases from 0.1 to $3.0 \mathrm{kPa}, R_{\text {stom }}$ should increase about ten-fold, increasing two-fold between 1.0 and $2.0 \mathrm{kPa}$, similar to observation in a 35-year-old oak stand (Granier and Bréda, 1996). 
We examined the expected response of $R_{\text {stom }}$ to $U$ by converting $D$ in equation 13 to $U$ based on the relationship between $D$ and $U$ (from Fig. 6b). Estimated $R_{\text {stom }}$ increased $38 \%$ over the range of $U$ and fell close to or within the $95 \%$ confidence intervals of the relationship between $R_{C}$ and $U$ (Fig. $4 \mathrm{e}$ ). As a result of the small contribution of $R_{\mathrm{A}}$ to $R_{\mathrm{T}}$, the variation of $R_{\mathrm{T}}$ was also highly correlated $(p<0.0001$, $R^{2}=0.79$ ) with the response of $R_{\text {stom }}$ to $D$; the slope was very close to unity, with $R_{\mathrm{T}}$ averaging only $2.8 \%$ higher than the expected values of $R_{\text {stom }}$ (Fig. 7). Thus, we failed to reject $\mathbf{H 3}$, concluding that the direct effect of $D$, acting as a driving gradient for plant transpiration, relative to its indirect effect, inducing stomatal closure (Fig. 1), dominates the response of transpiration to $U$. The average $D$, even in calm wind conditions of less than $<1 \mathrm{~m} \mathrm{~s}^{-1}$, was $>1 \mathrm{kPa}$ in this study, suggesting that much of the time the direct effect of $D$ was offset by $R_{\text {stom }}$ response to $D$, resulting in a constant $E_{\mathrm{C}}$ over the observed range of $U$.

\section{Conclusion}

This study assessed the responses of $J_{S}$ (as a surrogate for transpiration) to $U$ in a mixed hardwood stand under optimal meteorological condition for transpiration based on $T_{\mathrm{a}}$ and $\theta$. $J_{S}$ of the six species were insensitive or weakly responded to increasing $U$; stand-level transpiration appeared not to significantly change with $U$ (H1). The canopy of the broadleaved stand was well-coupled to the atmosphere, and thus had a low $R_{\mathrm{A}}$. Further decrease in $R_{\mathrm{A}}$ with increasing $U$ was readily offset by an increasing $R_{\mathrm{C}}(\mathbf{H 2})$. The increase in $R_{\mathrm{C}}$ was consistent with the theoretical increase in $R_{\text {stom }}$ with $D$ - which in turn increased with $U$ - keeping transpiration constant despite the increase of the driving force $(\mathbf{H 3})$. These results suggest that in similar forests the effect of $U$ on canopy transpiration is negligible. However, due to its effect on $D$ within the canopy and thus $R_{\text {stom }} U$ could have an important influence on $\mathrm{CO}_{2}$ uptake.

\section{Acknowledgments}

This research was supported by the Office of Science (BER) of the US Department of Energy through the Southeastern Regional Center (SERC) of the National Institute for Global Environmental Change (NIGEC), and through Terrestrial Carbon Processes (TCP) program.

\section{References}

Allen, R.G., 2005. Penman-Monteith equation. In: Hillel, D. (Ed.), Encyclopedia of Soils in the Environment. Elsevier/Academic Press, Oxford/Boston, pp. 180-188.

Aphalo, P.J., Jarvis, P.G., 1993. The boundary layer and the apparent responses of stomatal conductance to wind speed and to the mole fractions of $\mathrm{CO}_{2}$ and water vapor in the air. Plant Cell Environ. 16 (7), 771-783.

Avissar, R., Werth, D., 2005. Global hydroclimatological teleconnections resulting from tropical deforestation. J. Hydrometeorol. 6 (2), 134-145.

Bauerle, W.L., Bowden, J.D., 2011. Predicting transpiration response to climate change: insights on physiological and morphological interactions that modulate water exchange from leaves to canopies. Hortscience 46 (2), 163-166.

Bladon, K.D., Silins, U., Landhausser, S.M., Lieffers, V.J., 2006. Differential transpiration by three boreal tree species in response to increased evaporative demand after variable retention harvesting. Agric. For. Meteorol. 138 (1-4), 104-119.

Blanken, P.D., Black, T.A., 2004. The canopy conductance of a boreal aspen forest, Prince Albert National Park, Canada. Hydrol. Processes 18 (9), 1561-1578.

Caldwell, M.M., 1970. Plant gas exchange at high wind speeds. Plant Physiol. 46 (4), 535-537.

Campbell-Clause, J.M., 1998. Stomatal response of grapevines to wind. Aust. J. Exp. Agric. 38 (1), 77-82.

Campbell, G.S., Norman, J.M., 1998. An Introduction to Environmental Biophysics. Springer, New York.

Chapin III, F.S., 2002. Principles of Terrestrial Ecosystem Ecology. Springer, New York.

Chu, C.R., Hsieh, C.I., Wu, S.Y., Phillips, N.G., 2009. Transient response of sap flow to wind speed. J. Exp. Bot. 60 (1), 249-255.

Clausnitzer, F., Kostner, B., Schwarzel, K., Bernhofer, C., 2011. Relationships between canopy transpiration, atmospheric conditions and soil water availability - analyses of long-term sap-flow measurements in an old Norway spruce forest at the Ore Mountains/Germany. Agric. For. Meteorol. 151 (8), 1023-1034.
Daudet, F.A., Le Roux, X., Sinoquet, H., Adam, B., 1999. Wind speed and leaf boundary layer conductance variation within tree crown - consequences on leaf-toatmosphere coupling and tree functions. Agric. For. Meteorol. 97 (3), 171-185.

Dixon, M., Grace, J., 1984. Effect of wind on the transpiration of young trees. Ann. Bot. 53 (6), 811-819.

Grace, J., Malcolm, D.C., Bradbury, I.K., 1975. Effect of wind and humidity on lea diffusive resistance in Sitka spruce seedlings. J. Appl. Ecol. 12 (3), 931-940.

Grace, J., Russel, G., 1982. The effect of wind and a reduced supply of water on the growth and water relations of Festuca-Arundinacea Schreb. Ann. Bot. 49 (2), 217-225.

Granier, A., 1987. Sap flow measurements in Douglas-fir tree trunks by means of a new thermal method. Ann. Sci. For. 44 (1), 1-14.

Granier, A., Bréda, N., 1996. Modelling canopy conductance and stand transpiration of an oak forest from sap flow measurements. Ann. Sci. For. 53 (2-3), 537-546.

Granier, A., Loustau, D., Bréda, N., 2000. A generic model of forest canopy conductance dependent on climate, soil water availability and leaf area index. Ann. For. Sci. 57 (8), 755-765.

Gutiérrez, M.V., Meinzer,F.C.,Grantz, D.A., 1994. Regulation of transpiration in coffee hedgerows - covariation of environmental variables and apparent responses of stomata to wind and humidity. Plant Cell Environ. 17 (12), 1305-1313.

Harlow, W.M., Harrar, E.S., Hardin, J.W., White, F.M., 1996. Textbook of Dendrology. McGraw-Hill Series in Forest Resources. McGraw-Hill, New York

Hinckley, T.M., Brooks, J.R., Čermák, J., Ceulemans, R., Kučera, J., Meinzer, F.C., Roberts, D.A., 1994. Water flux in a hybrid poplar stand. Tree Physiol. 14 (7-9), 1005-1018.

Holmgren, B., Ovhed, M., Karlsson, P.S., 1996. Measuring and modeling stomatal and aerodynamic conductances of Mountain birch: implications for treeline dynamics. Arct. Alp. Res. 28 (4), 425-434.

Irmak, S., Mutiibwa, D., 2010. On the dynamics of canopy resistance: generalized linear estimation and relationships with primary micrometeorological variables. Water Resour. Res. 46, W08526.

Jarvis, P.G., 1976. The interpretation of the variations in leaf water potential and stomatal conductance found in canopies in the field. Philos. Trans. R. Soc. Lond. Ser. B: Biol. Sci. 273 (927), 593-610.

Jarvis, P.G., Mcnaughton, K.G., 1986. Stomatal control of transpiration - scaling up from leaf to region. Adv. Ecol. Res. 15, 1-49.

Jonard, F., Andre, F., Ponette, Q., Vincke, C., Jonard, M., 2011. Sap flux density and stomatal conductance of European beech and common oak trees in pure and mixed stands during the summer drought of 2003. J. Hydrol. 409 (1-2), $371-381$

Jones, H.G., 1992. Plants and Microclimate: A Quantitative Approach to Environmental Plant Physiology. Cambridge University Press, Cambridge, England, New York, NY, USA.

Juang, J.Y., Porporato, A., Stoy, P.C., Siqueira, M.S., Oishi, A.C., Detto, M., Kim, H.S. Katul, G., 2007. Hydrologic and atmospheric controls on initiation of convective precipitation events. Water Resour. Res. 43 (3.).

Katsoulas, N., Baille, A., Kittas, C., 2007. Leaf boundary layer conductance in ventilated greenhouses: an experimental approach. Agric. For. Meteorol. 144 (3-4) 180-192.

Katul, G.G., Palmroth, S., Oren, R., 2009. Leaf stomatal responses to vapour pressure deficit under current and $\mathrm{CO}_{2}$-enriched atmosphere explained by the economics of gas exchange. Plant Cell Environ. 32 (8), 968-979.

Kelliher, F.M., Leuning, R., Raupach, M.R., Schulze, E.D., 1995. Maximum conductances for evaporation from global vegetation types. Agric. For. Meteorol. 73 (1-2), 1-16.

Kelliher, F.M., Leuning, R., Schulze, E.D., 1993. Evaporation and canopy characteristics of coniferous forests and grasslands. Oecologia 95 (2), 153-163.

Kim, H.S., Oren, R., Hinckley, T.M., 2008. Actual and potential transpiration and carbon assimilation in an irrigated poplar plantation. Tree Physiol. 28 (4), 559-577.

Kitaya, Y., Shibuya, T., Yoshida, M., Kiyota, M., 2004. Effects of air velocity on photosynthesis of plant canopies under elevated $\mathrm{CO}_{2}$ levels in a plant culture system. Adv. Space Res. 34 (7), 1466-1469.

Komatsu, H., Kang, Y.H., Kume, T., Yoshifuji, N., Hotta, N., 2006. Transpiration from a Cryptomeria japonica plantation, part 1: aerodynamic control of transpiration. Hydrol. Processes 20 (6), 1309-1320.

Konings, A.G., Dekker, S.C., Rietkerk, M., Katul, G.G., 2011. Drought sensitivity of patterned vegetation determined by rainfall-land surface feedbacks. J. Geophys. Res.-Biogeo. 116.

Köstner, B.M.M., Schulze, E.-D., Kelliher, F.M., Hollinger, D.Y., Byers, J.N., Hunt, J.E., McSeveny, T.M., Meserth, R., Weir, P.L., 1992. Transpiration and canopy conductance in a pristine broad-leaved forest of Nothofagus - an analysis of xylem sap flow and eddy-correlation measurements. Oecologia 91 (3), 350-359.

Kumagai, T., Saitoh, T.M., Sato, Y., Morooka, T., Manfroi, O.J., Kuraji, K., Suzuki, M., 2004. Transpiration, canopy conductance and the decoupling coefficient of a lowland mixed dipterocarp forest in Sarawak, Borneo: dry spell effects. J. Hydrol. 287 (1-4), 237-251

Kupper, P., Sõber, J., Sellin, A., Lõhmus, K., Tullus, A., Räim, O., Lubenets, K., Tulva, I., Uri, V., Zobel, M., Kull, O., Sõber, A., 2011. An experimental facility for free air humidity manipulation (FAHM) can alter water flux through deciduous tree canopy. Environ. Exp. Bot. 72 (3), 432-438.

Launiainen, S., Katul, G.G., Kolari, P., Vesala, T., Hari, P., 2011. Empirical and optima stomatal controls on leaf and ecosystem level $\mathrm{CO}_{2}$ and $\mathrm{H}_{2} \mathrm{O}$ exchange rates. Agric For. Meteorol. 151 (12), 1672-1689.

Lei, H., Zhi-Shan, Z., Xin-Rong, L., 2010. Sap flow of Artemisia ordosica and the influence of environmental factors in a evegetated desert area: Tengger Desert, China. Hydrol. Processes 24, 1248-1253. 
Lindroth, A., 1993. Aerodynamic and canopy resistance of short-rotation forest in relation to leaf area index and climate. Boundary-Layer Meteorol. 66 (3), $265-279$.

Lohammar, T., Larsson, S., Linder, S., Falk, S.O., 1980. FAST: simulation models of gaseous exchange in Scots pine. Ecol. Bull. 32, 505-523.

Lu, P., Urban, L., Zhao, P., 2004. Granier's thermal dissipation probe (TDP) method for measuring sap flow in trees: theory and practice. Acta Bot. Sin. 46 (6), 631-646.

Morris, J., Mann, L., Collopy, J., 1998. Transpiration and canopy conductance in a eucalypt plantation using shallow saline groundwater. Tree Physiol. 18 (8-9), 547-555.

Novel, P.S., 2005. Physicochemical and Environmental Plant Physiology. Elsevier, Burlington.

Oishi, A.C., Oren, R., Novick, K.A., Palmroth, S., Katul, G.G., 2010. Interannual invariability of forest evapotranspiration and its consequence to water flow downstream. Ecosystems 13 (3), 421-436.

Oishi, A.C., Oren, R., Stoy, P.C., 2008. Estimating components of forest evapotranspiration: a footprint approach for scaling sap flux measurement. Agric. For. Meteorol. 148 (11), 1719-1732.

Oren, R., Pataki, D.E., 2001. Transpiration in response to variation in microclimate and soil moisture in southeastern deciduous forests. Oecologia 127 (4), 549-559.

Oren, R., Phillips, N., Katul, G., Ewers, B.E., Pataki, D.E., 1998. Scaling xylem sap flux and soil water balance and calculating variance: a method for partitioning water flux in forests. Ann. Sci. For. 55 (1-2), 191-216.

Oren, R., Sperry, J.S., Katul, G.G., Pataki, D.E., Ewers, B.E., Phillips, N., Schäfer, K.V.R., 1999. Survey and synthesis of intra- and interspecific variation in stomatal sensitivity to vapour pressure deficit. Plant Cell Environ. 22 (12), 1515-1526.

Pataki, D.E., Oren, R., 2003. Species differences in stomatal control of water loss at the canopy scale in a mature bottomland deciduous forest. Adv. Water Resour. 26 (12), 1267-1278.

Pereira, D.D., de Mello, C.R., da Silva, A.M., Yanagi, S.D.M., 2010. Evapotranspiration and estimation of aerodynamic and stomatal conductance in a fragment of Atlantic Forest in Mantiqueira Range region, MG. Cerne 16 (1), 32-40.

Perry, D.A., 2008. Forest Ecosystems. Johns Hopkins University Press, Baltimore.

Phillips, N., Oren, R., 2001. Intra- and inter-annual variation in transpiration of a pine forest. Ecol. Appl. 11 (2), 385-396.

Roberts, J., 1983. Forest transpiration - a conservative hydrological process. J. Hydrol. $66(1-4), 133-141$.

Running, S.W., Hunt, E.R., 1993. Generalization of a Forest Ecosystem Process Model for Other Biomes, BIOME-BGC, and an Application for Global-Scale Models. Scaling Physiological Processes: Leaf to Globe. Academic Press, San Diego.

Schäfer, K.V.R., Oren, R., Ellsworth, D.S., Lai, C., Herrick, J.D., Finzi, A.C., Richter, D.D. Katul, G.G., 2003. Exposure to an enriched $\mathrm{CO}_{2}$ atmosphere alters carbon assimilation and allocation in a pine forest ecosystem. Global Change Biol. 9 (10) 1378-1400.
Schäfer, K.V.R., Oren, R., Tenhunen, J.D., 2000. The effect of tree height on crown level stomatal conductance. Plant Cell Environ. 23 (4), 365-375.

Schuepp, P.H., 1993. Tansley review no. 59 leaf boundary-layers. New Phytol. 125 (3), 477-507.

Stewart, J.B., 1988. Modeling surface conductance of pine forest. Agric. For. Meteorol. $43(1), 19-35$.

Stokes, V.J., Morecroft, M.D., Morison, J.I.L., 2006. Boundary layer conductance for contrasting leaf shapes in a deciduous broadleaved forest canopy. Agric. For Meteorol. 139 (1-2), 40-54.

Stoy, P.C., Katul, G.G., Siqueira, M.B.S., Juang, J.Y., McCarthy, H.R., Kim, H.S., Oishi, A.C., Oren, R., 2005. Variability in net ecosystem exchange from hourly to interannual time scales at adjacent pine and hardwood forests: a wavelet analysis. Tree Physiol. 25 (7), 887-902.

Stoy, P.C., Katul, G.G, Siqueira, M.B.S, Juang J.Y, Novick, K.A., McCarthy, H.R., Oishi, A.C., Uebelherr, J.M., Kim, H.S., Oren, R., 2006. Separating the effects of climate and vegetation on evapotranspiration along a successional chronosequence in the southeastern US. Global Change Biol. 12 (11), 2115-2135.

Tatarinov, F.A., Kucera, J., Cienciala, E., 2005. The analysis of physical background of tree sap flow measurement based on thermal methods. Meas. Sci. Technol. 16 (5), 1157-1169.

Taylor, P.., Nuberg, I.K., Hatton, T.J., 2001. Enhanced transpiration in response to wind effects at the edge of a blue gum (Eucalyptus globulus) plantation. Tree Physiol. 21 (6), 403-408.

Ward, E.J., Oren, R., Sigurdsson, B.D., Jarvis, P.G., Linder, S., 2008. Fertilization effects on mean stomatal conductance are mediated through changes in the hydraulic attributes of mature Norway spruce trees. Tree Physiol. 28 (4), 579-596.

Waring, R.H., 2007. Forest Ecosystems: Analysis at Multiple Scales. Elsevier/Academic Press, Amsterdam, Boston.

Wilson, K.B., Baldocchi, D.D., Aubinet, M., Berbigier, P., Bernhofer, C., Dolman, H., Falge, E., Field, C., Goldstein, A., Granier, A., Grelle, A., Halldor, T., Hollinger, D. Katul, G., Law, B.E., Lindroth, A., Meyers, T., Moncrieff, J., Monson, R., Oechel, W. Tenhunen, J., Valentini, R., Verma, S., Vesala, T., Wofsy, S., 2002. Energy partitioning between latent and sensible heat flux during the warm season at FLUXNET sites. Water Resour. Res. 38, 1294-1304.

Wullschleger, S.D., Childs, K.W., King, A.W., Hanson, P.J., 2011. A model of heat transfer in sapwood and implications for sap flux density measurements using thermal dissipation probes. Tree Physiol. 31 (6), 669-679.

Xu, M., Chang, C.-P., Fu, C., Qi, Y., Robock, A., Robinson, D., Zhang, H., 2006. Steady decline of east Asian monsoon winds, 1969-2000: evidence from direct ground measurements of wind speed. J. Geophys. Res. -Atmos. 111 (D24)

Zalesny, R.S., Wiese, A.H., Bauer, E.O., Riemenschneider, D.E., 2006. Sapflow of hybrid poplar (Populus nigra L. $\times$ P-maximowiczii A. Henry 'NM6') during phytoremediation of landfill leachate. Biomass Bioenergy 30 (8-9), 784L 793. 